\title{
The Cross-Section of Expected Stock Returns
}

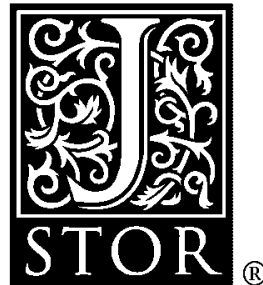

\author{
Eugene F. Fama; Kenneth R. French
}

The Journal of Finance, Vol. 47, No. 2. (Jun., 1992), pp. 427-465.

Stable URL:

http://links.jstor.org/sici?sici=0022-1082\%28199206\%2947\%3A2\%3C427\%3ATCOESR\%3E2.0.CO\%3B2-N

The Journal of Finance is currently published by American Finance Association.

Your use of the JSTOR archive indicates your acceptance of JSTOR's Terms and Conditions of Use, available at http://www.jstor.org/about/terms.html. JSTOR's Terms and Conditions of Use provides, in part, that unless you have obtained prior permission, you may not download an entire issue of a journal or multiple copies of articles, and you may use content in the JSTOR archive only for your personal, non-commercial use.

Please contact the publisher regarding any further use of this work. Publisher contact information may be obtained at http://www.jstor.org/journals/afina.html.

Each copy of any part of a JSTOR transmission must contain the same copyright notice that appears on the screen or printed page of such transmission.

JSTOR is an independent not-for-profit organization dedicated to creating and preserving a digital archive of scholarly journals. For more information regarding JSTOR, please contact support@jstor.org. 


\title{
The Cross-Section of Expected Stock Returns
}

\author{
EUGENE F. FAMA and KENNETH R. FRENCH*
}

\begin{abstract}
Two easily measured variables, size and book-to-market equity, combine to capture the cross-sectional variation in average stock returns associated with market $\beta$, size, leverage, book-to-market equity, and earnings-price ratios. Moreover, when the tests allow for variation in $\beta$ that is unrelated to size, the relation between market $\beta$ and average return is flat, even when $\beta$ is the only explanatory variable.
\end{abstract}

THE ASSET-PRICING MODEL OF Sharpe (1964), Lintner (1965), and Black (1972) has long shaped the way academics and practitioners think about average returns and risk. The central prediction of the model is that the market portfolio of invested wealth is mean-variance efficient in the sense of Markowitz (1959). The efficiency of the market portfolio implies that (a) expected returns on securities are a positive linear function of their market $\beta \mathrm{s}$ (the slope in the regression of a security's return on the market's return), and (b) market $\beta$ s suffice to describe the cross-section of expected returns.

There are several empirical contradictions of the Sharpe-Lintner-Black (SLB) model. The most prominent is the size effect of Banz (1981). He finds that market equity, ME (a stock's price times shares outstanding), adds to the explanation of the cross-section of average returns provided by market $\beta \mathrm{s}$. Average returns on small (low ME) stocks are too high given their $\beta$ estimates, and average returns on large stocks are too low.

Another contradiction of the SLB model is the positive relation between leverage and average return documented by Bhandari (1988). It is plausible that leverage is associated with risk and expected return, but in the SLB model, leverage risk should be captured by market $\beta$. Bhandari finds, however, that leverage helps explain the cross-section of average stock returns in tests that include size (ME) as well as $\beta$.

Stattman (1980) and Rosenberg, Reid, and Lanstein (1985) find that average returns on U.S. stocks are positively related to the ratio of a firm's book value of common equity, $\mathrm{BE}$, to its market value, $\mathrm{ME}$. Chan, Hamao, and Lakonishok (1991) find that book-to-market equity, BE/ME, also has a strong role in explaining the cross-section of average returns on Japanese stocks.

\footnotetext{
* Graduate School of Business, University of Chicago, 1101 East 58th Street, Chicago, IL 60637. We acknowledge the helpful comments of David Booth, Nai-fu Chen, George Constantinides, Wayne Ferson, Edward George, Campbell Harvey, Josef Lakonishok, Rex Sinquefield, René Stulz, Mark Zmijeweski, and an anonymous referee. This research is supported by the National Science Foundation (Fama) and the Center for Research in Security Prices (French).
} 
Finally, Basu (1983) shows that earnings-price ratios $(\mathrm{E} / \mathrm{P})$ help explain the cross-section of average returns on U.S. stocks in tests that also include size and market $\beta$. Ball (1978) argues that $\mathrm{E} / \mathrm{P}$ is a catch-all proxy for unnamed factors in expected returns; $\mathrm{E} / \mathrm{P}$ is likely to be higher (prices are lower relative to earnings) for stocks with higher risks and expected returns, whatever the unnamed sources of risk.

Ball's proxy argument for E/P might also apply to size (ME), leverage, and book-to-market equity. All these variables can be regarded as different ways to scale stock prices, to extract the information in prices about risk and expected returns (Keim (1988)). Moreover, since E/P, ME, leverage, and $\mathrm{BE} / \mathrm{ME}$ are all scaled versions of price, it is reasonable to expect that some of them are redundant for describing average returns. Our goal is to evaluate the joint roles of market $\beta$, size, $\mathrm{E} / \mathrm{P}$, leverage, and book-to-market equity in the cross-section of average returns on NYSE, AMEX, and NASDAQ stocks.

Black, Jensen, and Scholes (1972) and Fama and MacBeth (1973) find that, as predicted by the SLB model, there is a positive simple relation between average stock returns and $\beta$ during the pre-1969 period. Like Reinganum (1981) and Lakonishok and Shapiro (1986), we find that the relation between $\beta$ and average return disappears during the more recent 1963-1990 period, even when $\beta$ is used alone to explain average returns. The appendix shows that the simple relation between $\beta$ and average return is also weak in the 50-year 1941-1990 period. In short, our tests do not support the most basic prediction of the SLB model, that average stock returns are positively related to market $\beta$ s.

Unlike the simple relation between $\beta$ and average return, the univariate relations between average return and size, leverage, $\mathrm{E} / \mathrm{P}$, and book-to-market equity are strong. In multivariate tests, the negative relation between size and average return is robust to the inclusion of other variables. The positive relation between book-to-market equity and average return also persists in competition with other variables. Moreover, although the size effect has attracted more attention, book-to-market equity has a consistently stronger role in average returns. Our bottom-line results are: (a) $\beta$ does not seem to help explain the cross-section of average stock returns, and (b) the combination of size and book-to-market equity seems to absorb the roles of leverage and $\mathrm{E} / \mathrm{P}$ in average stock returns, at least during our 1963-1990 sample period.

If assets are priced rationally, our results suggest that stock risks are multidimensional. One dimension of risk is proxied by size, ME. Another dimension of risk is proxied by $\mathrm{BE} / \mathrm{ME}$, the ratio of the book value of common equity to its market value.

It is possible that the risk captured by $\mathrm{BE} / \mathrm{ME}$ is the relative distress factor of Chan and Chen (1991). They postulate that the earning prospects of firms are associated with a risk factor in returns. Firms that the market judges to have poor prospects, signaled here by low stock prices and high ratios of book-to-market equity, have higher expected stock returns (they are penalized with higher costs of capital) than firms with strong prospects. It is 
also possible, however, that $\mathrm{BE} / \mathrm{ME}$ just captures the unraveling (regression toward the mean) of irrational market whims about the prospects of firms.

Whatever the underlying economic causes, our main result is straightforward. Two easily measured variables, size (ME) and book-to-market equity (BE/ME), provide a simple and powerful characterization of the cross-section of average stock returns for the 1963-1990 period.

In the next section we discuss the data and our approach to estimating $\beta$. Section II examines the relations between average return and $\beta$ and between average return and size. Section III examines the roles of $\mathrm{E} / \mathrm{P}$, leverage, and book-to-market equity in average returns. In sections IV and V, we summarize, interpret, and discuss applications of the results.

\section{Preliminaries}

\section{A. Data}

We use all nonfinancial firms in the intersection of (a) the NYSE, AMEX, and NASDAQ return files from the Center for Research in Security Prices (CRSP) and (b) the merged COMPUSTAT annual industrial files of incomestatement and balance-sheet data, also maintained by CRSP. We exclude financial firms because the high leverage that is normal for these firms probably does not have the same meaning as for nonfinancial firms, where high leverage more likely indicates distress. The CRSP returns cover NYSE and AMEX stocks until 1973 when NASDAQ returns also come on line. The COMPUSTAT data are for 1962-1989. The 1962 start date reflects the fact that book value of common equity (COMPUSTAT item 60), is not generally available prior to 1962. More important, COMPUSTAT data for earlier years have a serious selection bias; the pre-1962 data are tilted toward big historically successful firms.

To ensure that the accounting variables are known before the returns they are used to explain, we match the accounting data for all fiscal yearends in calendar year $t-1$ (1962-1989) with the returns for July of year $t$ to June of $t+1$. The 6-month (minimum) gap between fiscal yearend and the return tests is conservative. Earlier work (e.g., Basu (1983)) often assumes that accounting data are available within three months of fiscal yearends. Firms are indeed required to file their $10-\mathrm{K}$ reports with the SEC within 90 days of their fiscal yearends, but on average $19.8 \%$ do not comply. In addition, more than $40 \%$ of the December fiscal yearend firms that do comply with the 90-day rule file on March 31, and their reports are not made public until April. (See Alford, Jones, and Zmijewski (1992).)

We use a firm's market equity at the end of December of year $t-1$ to compute its book-to-market, leverage, and earnings-price ratios for $t-1$, and we use its market equity for June of year $t$ to measure its size. Thus, to be included in the return tests for July of year $t$, a firm must have a CRSP stock price for December of year $t-1$ and June of year $t$. It must also have monthly returns for at least 24 of the 60 months preceding July of year $t$ (for 
"pre-ranking" $\beta$ estimates, discussed below). And the firm must have COMPUSTAT data on total book assets (A), book equity (BE), and earnings (E), for its fiscal year ending in (any month of) calendar year $t-1$.

Our use of December market equity in the $\mathrm{E} / \mathrm{P}, \mathrm{BE} / \mathrm{ME}$, and leverage ratios is objectionable for firms that do not have December fiscal yearends because the accounting variable in the numerator of a ratio is not aligned with the market value in the denominator. Using $\mathrm{ME}$ at fiscal yearends is also problematic; then part of the cross-sectional variation of a ratio for a given year is due to market-wide variation in the ratio during the year. For example, if there is a general fall in stock prices during the year, ratios measured early in the year will tend to be lower than ratios measured later. We can report, however, that the use of fiscal-yearend MEs, rather than December MEs, in the accounting ratios has little impact on our return tests.

Finally, the tests mix firms with different fiscal yearends. Since we match accounting data for all fiscal yearends in calendar year $t-1$ with returns for July of $t$ to June of $t+1$, the gap between the accounting data and the matching returns varies across firms. We have done the tests using the smaller sample of firms with December fiscal yearends with similar results.

\section{B. Estimating Market $\beta$ s}

Our asset-pricing tests use the cross-sectional regression approach of Fama and MacBeth (1973). Each month the cross-section of returns on stocks is regressed on variables hypothesized to explain expected returns. The timeseries means of the monthly regression slopes then provide standard tests of whether different explanatory variables are on average priced.

Since size, $\mathrm{E} / \mathrm{P}$, leverage, and $\mathrm{BE} / \mathrm{ME}$ are measured precisely for individual stocks, there is no reason to smear the information in these variables by using portfolios in the Fama-MacBeth (FM) regressions. Most previous tests use portfolios because estimates of market $\beta \mathrm{s}$ are more precise for portfolios. Our approach is to estimate $\beta$ s for portfolios and then assign a portfolio's $\beta$ to each stock in the portfolio. This allows us to use individual stocks in the FM asset-pricing tests.

\section{B.1. $\beta$ Estimation: Details}

In June of each year, all NYSE stocks on CRSP are sorted by size (ME) to determine the NYSE decile breakpoints for ME. NYSE, AMEX, and NASDAQ stocks that have the required CRSP-COMPUSTAT data are then allocated to 10 size portfolios based on the NYSE breakpoints. (If we used stocks from all three exchanges to determine the ME breakpoints, most portfolios would include only small stocks after 1973, when NASDAQ stocks are added to the sample.)

We form portfolios on size because of the evidence of Chan and Chen (1988) and others that size produces a wide spread of average returns and $\beta \mathrm{s}$. Chan and Chen use only size portfolios. The problem this creates is that size and the $\beta \mathrm{s}$ of size portfolios are highly correlated $(-0.988$ in their data), so 
asset-pricing tests lack power to separate size from $\beta$ effects in average returns.

To allow for variation in $\beta$ that is unrelated to size, we subdivide each size decile into 10 portfolios on the basis of pre-ranking $\beta$ s for individual stocks. The pre-ranking $\beta$ s are estimated on 24 to 60 monthly returns (as available) in the 5 years before July of year $t$. We set the $\beta$ breakpoints for each size decile using only NYSE stocks that satisfy our COMPUSTAT-CRSP data requirements for year $t-1$. Using NYSE stocks ensures that the $\beta$ breakpoints are not dominated after 1973 by the many small stocks on NASDAQ. Setting $\beta$ breakpoints with stocks that satisfy our COMPUSTAT-CRSP data requirements guarantees that there are firms in each of the 100 size- $\beta$ portfolios.

After assigning firms to the size- $\beta$ portfolios in June, we calculate the equal-weighted monthly returns on the portfolios for the next 12 months, from July to June. In the end, we have post-ranking monthly returns for July 1963 to December 1990 on 100 portfolios formed on size and pre-ranking $\beta \mathrm{s}$. We then estimate $\beta$ s using the full sample (330 months) of post-ranking returns on each of the 100 portfolios, with the CRSP value-weighted portfolio of NYSE, AMEX, and (after 1972) NASDAQ stocks used as the proxy for the market. We have also estimated $\beta$ s using the value-weighted or the equalweighted portfolio of NYSE stocks as the proxy for the market. These $\beta \mathrm{s}$ produce inferences on the role of $\beta$ in average returns like those reported below.

We estimate $\beta$ as the sum of the slopes in the regression of the return on a portfolio on the current and prior month's market return. (An additional lead and lag of the market have little effect on these sum $\beta \mathrm{s}$.) The sum $\beta \mathrm{s}$ are meant to adjust for nonsynchronous trading (Dimson (1979)). Fowler and Rorke (1983) show that sum $\beta$ s are biased when the market return is autocorrelated. The 1st- and 2nd-order autocorrelations of the monthly market returns for July 1963 to December 1990 are 0.06 and -0.05 , both about 1 standard error from 0 . If the Fowler-Rorke corrections are used, they lead to trivial changes in the $\beta \mathrm{s}$. We stick with the simpler sum $\beta \mathrm{s}$. Appendix Table AI shows that using sum $\beta$ s produces large increases in the $\beta \mathrm{s}$ of the smallest ME portfolios and small declines in the $\beta$ s of the largest ME portfolios.

Chan and Chen (1988) show that full-period $\beta$ estimates for portfolios can work well in tests of the SLB model, even if the true $\beta \mathrm{s}$ of the portfolios vary through time, if the variation in the $\beta \mathrm{s}$ is proportional,

$$
\beta_{j t}-\beta_{j}=k_{t}\left(\beta_{j}-\beta\right),
$$

where $\beta_{j t}$ is the true $\beta$ for portfolio $j$ at time $t, \beta_{j}$ is the mean of $\beta_{j t}$ across $t$, and $\beta$ is the mean of the $\beta_{j}$. The Appendix argues that (1) is a good approximation for the variation through time in the true $\beta \mathrm{s}$ of portfolios $(j)$ formed on size and $\beta$. For diehard $\beta$ fans, sure to be skeptical of our results on the weak role of $\beta$ in average stock returns, we can also report that the results stand up to robustness checks that use 5-year pre-ranking $\beta \mathrm{s}$, or 5 -year post-ranking $\beta \mathrm{s}$, instead of the full-period post-ranking $\beta \mathrm{s}$. 
We allocate the full-period post-ranking $\beta$ of a size- $\beta$ portfolio to each stock in the portfolio. These are the $\beta$ s that will be used in the Fama-MacBeth cross-sectional regressions for individual stocks. We judge that the precision of the full-period post-ranking portfolio $\beta \mathrm{s}$, relative to the imprecise $\beta$ estimates that would be obtained for individual stocks, more than makes up for the fact that true $\beta$ s are not the same for all stocks in a portfolio. And note that assigning full-period portfolio $\beta$ s to stocks does not mean that a stock's $\beta$ is constant. A stock can move across portfolios with year-to-year changes in the stock's size (ME) and in the estimates of its $\beta$ for the preceding 5 years.

\section{B.2. $\beta$ Estimates}

Table I shows that forming portfolios on size and pre-ranking $\beta \mathrm{s}$, rather than on size alone, magnifies the range of full-period post-ranking $\beta \mathrm{s}$. Sorted on size alone, the post-ranking $\beta$ s range from 1.44 for the smallest $\mathrm{ME}$ portfolio to 0.92 for the largest. This spread of $\beta$ s across the 10 size deciles is smaller than the spread of post-ranking $\beta$ s produced by the $\beta$ sort of any size decile. For example, the post-ranking $\beta$ s for the 10 portfolios in the smallest size decile range from 1.05 to 1.79 . Across all 100 size- $\beta$ portfolios, the post-ranking $\beta$ s range from 0.53 to 1.79 , a spread 2.4 times the spread, 0.52 , obtained with size portfolios alone.

Two other facts about the $\beta$ s are important. First, in each size decile the post-ranking $\beta \mathrm{s}$ closely reproduce the ordering of the pre-ranking $\beta \mathrm{s}$. We take this to be evidence that the pre-ranking $\beta$ sort captures the ordering of true post-ranking $\beta \mathrm{s}$. (The appendix gives more evidence on this important issue.) Second, the $\beta$ sort is not a refined size sort. In any size decile, the average values of $\ln (\mathrm{ME})$ are similar across the $\beta$-sorted portfolios. Thus the pre-ranking $\beta$ sort achieves its goal. It produces strong variation in postranking $\beta \mathrm{s}$ that is unrelated to size. This is important in allowing our tests to distinguish between $\beta$ and size effects in average returns.

\section{II. $\beta$ and Size}

The Sharpe-Lintner-Black (SLB) model plays an important role in the way academics and practitioners think about risk and the relation between risk and expected return. We show next that when common stock portfolios are formed on size alone, there seems to be evidence for the model's central prediction: average return is positively related to $\beta$. The $\beta$ s of size portfolios are, however, almost perfectly correlated with size, so tests on size portfolios are unable to disentangle $\beta$ and size effects in average returns. Allowing for variation in $\beta$ that is unrelated to size breaks the logjam, but at the expense of $\beta$. Thus, when we subdivide size portfolios on the basis of pre-ranking $\beta \mathrm{s}$, we find a strong relation between average return and size, but no relation between average return and $\beta$. 


\section{A. Informal Tests}

Table II shows post-ranking average returns for July 1963 to December 1990 for portfolios formed from one-dimensional sorts of stocks on size or $\beta$. The portfolios are formed at the end of June each year and their equalweighted returns are calculated for the next 12 months. We use returns for July to June to match the returns in later tests that use the accounting data. When we sort on just size or 5-year pre-ranking $\beta \mathrm{s}$, we form 12 portfolios. The middle 8 cover deciles of size or $\beta$. The 4 extreme portfolios $(1 \mathrm{~A}, 1 \mathrm{~B}, 10 \mathrm{~A}$, and 10B) split the bottom and top deciles in half.

Table II shows that when portfolios are formed on size alone, we observe the familiar strong negative relation between size and average return (Banz (1981)), and a strong positive relation between average return and $\beta$. Average returns fall from $1.64 \%$ per month for the smallest ME portfolio to $0.90 \%$ for the largest. Post-ranking $\beta$ s also decline across the 12 size portfolios, from 1.44 for portfolio $1 \mathrm{~A}$ to 0.90 for portfolio $10 \mathrm{~B}$. Thus, a simple size sort seems to support the SLB prediction of a positive relation between $\beta$ and average return. But the evidence is muddied by the tight relation between size and the $\beta$ s of size portfolios.

The portfolios formed on the basis of the ranked market $\beta \mathrm{s}$ of stocks in Table II produce a wider range of $\beta$ s (from 0.81 for portfolio $1 \mathrm{~A}$ to 1.73 for 10B) than the portfolios formed on size. Unlike the size portfolios, the $\beta$-sorted portfolios do not support the SLB model. There is little spread in average returns across the $\beta$ portfolios, and there is no obvious relation between $\beta$ and average returns. For example, although the two extreme portfolios, $1 \mathrm{~A}$ and $10 \mathrm{~B}$, have much different $\beta \mathrm{s}$, they have nearly identical average returns (1.20\% and $1.18 \%$ per month). These results for $1963-1990$ confirm Reinganum's (1981) evidence that for $\beta$-sorted portfolios, there is no relation between average return and $\beta$ during the 1964-1979 period.

The 100 portfolios formed on size and then pre-ranking $\beta$ in Table I clarify the contradictory evidence on the relation between $\beta$ and average return produced by portfolios formed on size or $\beta$ alone. Specifically, the two-pass sort gives a clearer picture of the separate roles of size and $\beta$ in average returns. Contrary to the central prediction of the SLB model, the second-pass $\beta$ sort produces little variation in average returns. Although the post-ranking $\beta \mathrm{s}$ in Table I increase strongly in each size decile, average returns are flat or show a slight tendency to decline. In contrast, within the columns of the average return and $\beta$ matrices of Table I, average returns and $\beta$ s decrease with increasing size.

The two-pass sort on size and $\beta$ in Table I says that variation in $\beta$ that is tied to size is positively related to average return, but variation in $\beta$ unrelated to size is not compensated in the average returns of 1963-1990. The proper inference seems to be that there is a relation between size and average return, but controlling for size, there is no relation between $\beta$ and average return. The regressions that follow confirm this conclusion, and they produce another that is stronger. The regressions show that when one allows 
Table I

Average Returns, Post-Ranking $\beta$ s and Average Size For Portfolios Formed on Size and then $\beta$ : Stocks Sorted on ME (Down) then Pre-Ranking $\beta$ (Across):

\section{July 1963 to December 1990}

Portfolios are formed yearly. The breakpoints for the size (ME, price times shares outstanding) deciles are determined in June of year $t(t=1963-1990)$ using all NYSE stocks on CRSP. All NYSE, AMEX, and NASDAQ stocks that meet the CRSP-COMPUSTAT data requirements are allocated to the 10 size portfolios using the NYSE breakpoints. Each size decile is subdivided into $10 \beta$ portfolios using pre-ranking $\beta$ s of individual stocks, estimated with 2 to 5 years of monthly returns (as available) ending in June of year $t$. We use only NYSE stocks that meet the CRSP-COMPUSTAT data requirements to establish the $\beta$ breakpoints. The equal-weighted monthly returns on the resulting 100 portfolios are then calculated for July of year $t$ to June of year $t+1$.

The post-ranking $\beta$ s use the full (July 1963 to December 1990) sample of post-ranking returns for each portfolio. The pre- and post-ranking $\beta$ s (here and in all other tables) are the sum of the slopes from a regression of monthly returns on the current and prior month's returns on the value-weighted portfolio of NYSE, AMEX, and (after 1972) NASDAQ stocks. The average return is the time-series average of the monthly equal-weighted portfolio returns, in percent. The average size of a portfolio is the time-series average of monthly averages of $\ln (\mathrm{ME})$ for stocks in the portfolio at the end of June of each year, with ME denominated in millions of dollars.

The average number of stocks per month for the size- $\beta$ portfolios in the smallest size decile varies from 70 to 177 . The average number of stocks for the size- $\beta$ portfolios in size deciles 2 and 3 is between 15 and 41 , and the average number for the largest 7 size deciles is between 11 and 22 .

The All column shows statistics for equal-weighted size-decile (ME) portfolios. The All row shows statistics for equal-weighted portfolios of the stocks in each $\beta$ group.

\begin{tabular}{lcccccccccccc}
\hline & All & Low- $\beta$ & $\beta-2$ & $\beta-3$ & $\beta-4$ & $\beta-5$ & $\beta-6$ & $\beta-7$ & $\beta-8$ & $\beta-9$ & High- $\beta$ \\
\hline & & \multicolumn{7}{c}{ Panel A: Average } & Monthly & Returns (in Percent) \\
\hline All & 1.25 & 1.34 & 1.29 & 1.36 & 1.31 & 1.33 & 1.28 & 1.24 & 1.21 & 1.25 & 1.14 \\
Small-ME & 1.52 & 1.71 & 1.57 & 1.79 & 1.61 & 1.50 & 1.50 & 1.37 & 1.63 & 1.50 & 1.42 \\
ME-2 & 1.29 & 1.25 & 1.42 & 1.36 & 1.39 & 1.65 & 1.61 & 1.37 & 1.31 & 1.34 & 1.11 \\
ME-3 & 1.24 & 1.12 & 1.31 & 1.17 & 1.70 & 1.29 & 1.10 & 1.31 & 1.36 & 1.26 & 0.76 \\
ME-4 & 1.25 & 1.27 & 1.13 & 1.54 & 1.06 & 1.34 & 1.06 & 1.41 & 1.17 & 1.35 & 0.98 \\
ME-5 & 1.29 & 1.34 & 1.42 & 1.39 & 1.48 & 1.42 & 1.18 & 1.13 & 1.27 & 1.18 & 1.08 \\
ME-6 & 1.17 & 1.08 & 1.53 & 1.27 & 1.15 & 1.20 & 1.21 & 1.18 & 1.04 & 1.07 & 1.02 \\
ME-7 & 1.07 & 0.95 & 1.21 & 1.26 & 1.09 & 1.18 & 1.11 & 1.24 & 0.62 & 1.32 & 0.76 \\
ME-8 & 1.10 & 1.09 & 1.05 & 1.37 & 1.20 & 1.27 & 0.98 & 1.18 & 1.02 & 1.01 & 0.94 \\
ME-9 & 0.95 & 0.98 & 0.88 & 1.02 & 1.14 & 1.07 & 1.23 & 0.94 & 0.82 & 0.88 & 0.59 \\
Large-ME & 0.89 & 1.01 & 0.93 & 1.10 & 0.94 & 0.93 & 0.89 & 1.03 & 0.71 & 0.74 & 0.56
\end{tabular}


Table I-Continued

\begin{tabular}{|c|c|c|c|c|c|c|c|c|c|c|c|}
\hline & All & Low- $\beta$ & $\beta-2$ & $\beta-3$ & $\beta-4$ & $\beta-5$ & $\beta-6$ & $\beta-7$ & $\beta-8$ & $\beta-9$ & High $-\beta$ \\
\hline \multicolumn{12}{|c|}{ Panel B: Post-Ranking $\beta$ s } \\
\hline All & & 0.87 & 0.99 & 1.09 & 1.16 & 1.26 & 1.29 & 1.35 & 1.45 & 1.52 & 1.72 \\
\hline Small-ME & 1.44 & 1.05 & 1.18 & 1.28 & 1.32 & 1.40 & 1.40 & 1.49 & 1.61 & 1.64 & 1.79 \\
\hline ME-2 & 1.39 & 0.91 & 1.15 & 1.17 & 1.24 & 1.36 & 1.41 & 1.43 & 1.50 & 1.66 & 1.76 \\
\hline ME-3 & 1.35 & 0.97 & 1.13 & 1.13 & 1.21 & 1.26 & 1.28 & 1.39 & 1.50 & 1.51 & 1.75 \\
\hline ME-4 & 1.34 & 0.78 & 1.03 & 1.17 & 1.16 & 1.29 & 1.37 & 1.46 & 1.51 & 1.64 & 1.71 \\
\hline ME-5 & 1.25 & 0.66 & 0.85 & 1.12 & 1.15 & 1.16 & 1.26 & 1.30 & 1.43 & 1.59 & 1.68 \\
\hline ME-6 & 1.23 & 0.61 & 0.78 & 1.05 & 1.16 & 1.22 & 1.28 & 1.36 & 1.46 & 1.49 & 1.70 \\
\hline ME-7 & 1.17 & 0.57 & 0.92 & 1.01 & 1.11 & 1.14 & 1.26 & 1.24 & 1.39 & 1.34 & 1.60 \\
\hline ME-8 & 1.09 & 0.53 & 0.74 & 0.94 & 1.02 & 1.13 & 1.12 & 1.18 & 1.26 & 1.35 & 1.52 \\
\hline ME-9 & 1.03 & 0.58 & 0.74 & 0.80 & 0.95 & 1.06 & 1.15 & 1.14 & 1.21 & 1.22 & 1.42 \\
\hline Large-ME & 0.92 & 0.57 & 0.71 & 0.78 & 0.89 & 0.95 & 0.92 & 1.02 & 1.01 & 1.11 & 1.32 \\
\hline \multicolumn{12}{|c|}{ Panel C: Average Size (ln(ME)) } \\
\hline All & 4.11 & 3.86 & 4.26 & 4.33 & 4.41 & 4.27 & 4.32 & 4.26 & 4.19 & 4.03 & 3.77 \\
\hline Small-ME & 2.24 & 2.12 & 2.27 & 2.30 & 2.30 & 2.28 & 2.29 & 2.30 & 2.32 & 2.25 & 2.15 \\
\hline ME-2 & 3.63 & 3.65 & 3.68 & 3.70 & 3.72 & 3.69 & 3.70 & 3.69 & 3.69 & 3.70 & 3.68 \\
\hline ME-3 & 4.10 & 4.14 & 4.18 & 4.12 & 4.15 & 4.16 & 4.16 & 4.18 & 4.14 & 4.15 & 4.15 \\
\hline $\mathrm{ME}-4$ & 4.50 & 4.53 & 4.53 & 4.57 & 4.54 & 4.56 & 4.55 & 4.52 & 4.58 & 4.52 & 4.56 \\
\hline ME-5 & 4.89 & 4.91 & 4.91 & 4.93 & 4.95 & 4.93 & 4.92 & 4.93 & 4.92 & 4.92 & 4.95 \\
\hline ME-6 & 5.30 & 5.30 & 5.33 & 5.34 & 5.34 & 5.33 & 5.33 & 5.33 & 5.33 & 5.34 & 5.36 \\
\hline ME-7 & 5.73 & 5.73 & 5.75 & 5.77 & 5.76 & 5.73 & 5.77 & 5.77 & 5.76 & 5.72 & 5.76 \\
\hline ME-8 & 6.24 & 6.26 & 6.27 & 6.26 & 6.24 & 6.24 & 6.27 & 6.24 & 6.24 & 6.24 & 6.26 \\
\hline ME-9 & 6.82 & 6.82 & 6.84 & 6.82 & 6.82 & 6.81 & 6.81 & 6.81 & 6.81 & 6.80 & 6.83 \\
\hline Large-ME & 7.93 & 7.94 & 8.04 & 8.10 & 8.04 & 8.02 & 8.02 & 7.94 & 7.80 & 7.75 & 7.62 \\
\hline
\end{tabular}


Properties of Portfolios Formed on Size or Pre-Ranking $\beta$ :

July 1963 to December 1990

At the end of June of each year $t, 12$ portfolios are formed on the basis of ranked values of size (ME) or pre-ranking $\beta$. The pre-ranking $\beta$ s use 2 to 5 years (as available) of monthly returns ending in June of $t$. Portfolios 2-9 cover deciles of the ranking variables. The bottom and top 2 portfolios $(1 \mathrm{~A}, 1 \mathrm{~B}, 10 \mathrm{~A}$, and 10B) split the bottom and top deciles in half. The breakpoints for the ME portfolios are based on ranked values of ME for all NYSE stocks on CRSP. NYSE breakpoints for pre-ranking $\beta$ s are also used to form the $\beta$ portfolios. NYSE, AMEX, and NASDAQ stocks are then allocated to the size or $\beta$ portfolios using the NYSE breakpoints. We calculate each portfolio's monthly equal-weighted return for July of year $t$ to June of year $t+1$, and then reform the portfolios in June of $t+1$.

$\mathrm{BE}$ is the book value of common equity plus balance-sheet deferred taxes, $\mathrm{A}$ is total book assets, and $\mathrm{E}$ is earnings (income before extraordinary items, plus income-statement deferred taxes, minus preferred dividends). $\mathrm{BE}, \mathrm{A}$, and $\mathrm{E}$ are for each firm's latest fiscal year ending in calendar year $t-1$. The accounting ratios are measured using market equity $\mathrm{ME}$ in December of year $t-1$. Firm size $\ln (\mathrm{ME})$ is measured in June of year $t$, with ME denominated in millions of dollars.

The average return is the time-series average of the monthly equal-weighted portfolio returns, in percent. $\ln (\mathrm{ME})$, $\ln (\mathrm{BE} / \mathrm{ME}), \ln (\mathrm{A} / \mathrm{ME}), \ln (\mathrm{A} / \mathrm{BE}), \mathrm{E} / \mathrm{P}$, and $\mathrm{E} / \mathrm{P}$ dummy are the time-series averages of the monthly average values of these variables in each portfolio. Since the $\mathrm{E} / \mathrm{P}$ dummy is 0 when earnings are positive, and 1 when earnings are negative, $\mathrm{E} / \mathrm{P}$ dummy gives the average proportion of stocks with negative earnings in each portfolio.

$\beta$ is the time-series average of the monthly portfolio $\beta$ s. Stocks are assigned the post-ranking $\beta$ of the size $-\beta$ portfolio they are in at the end of June of year $t$ (Table I). These individual-firm $\beta \mathrm{s}$ are averaged to compute the monthly $\beta \mathrm{s}$ for each portfolio for July of year $t$ to June of year $t+1$.

Firms is the average number of stocks in the portfolio each month.

\begin{tabular}{|c|c|c|c|c|c|c|c|c|c|c|c|c|}
\hline & $1 \mathrm{~A}$ & $1 \mathrm{~B}$ & 2 & 3 & 4 & 5 & 6 & 7 & 8 & 9 & $10 \mathrm{~A}$ & $10 \mathrm{~B}$ \\
\hline \multicolumn{13}{|c|}{ Panel A: Portfolios Formed on Size } \\
\hline Return & 1.64 & 1.16 & 1.29 & 1.24 & 1.25 & 1.29 & 1.17 & 1.07 & 1.10 & 0.95 & 0.88 & 0.90 \\
\hline$\beta$ & 1.44 & 1.44 & 1.39 & 1.34 & 1.33 & 1.24 & 1.22 & 1.16 & 1.08 & 1.02 & 0.95 & 0.90 \\
\hline $\ln (\mathrm{ME})$ & 1.98 & 3.18 & 3.63 & 4.10 & 4.50 & 4.89 & 5.30 & 5.73 & 6.24 & 6.82 & 7.39 & 8.44 \\
\hline $\ln (\mathrm{BE} / \mathrm{ME})$ & -0.01 & -0.21 & -0.23 & -0.26 & -0.32 & -0.36 & -0.36 & -0.44 & -0.40 & -0.42 & -0.51 & -0.65 \\
\hline $\ln (\mathrm{A} / \mathrm{ME})$ & 0.73 & 0.50 & 0.46 & 0.43 & 0.37 & 0.32 & 0.32 & 0.24 & 0.29 & 0.27 & 0.17 & -0.03 \\
\hline $\ln (\mathrm{A} / \mathrm{BE})$ & 0.75 & 0.71 & 0.69 & 0.69 & 0.68 & 0.67 & 0.68 & 0.67 & 0.69 & 0.70 & 0.68 & 0.62 \\
\hline $\mathrm{E} / \mathrm{P}$ dummy & 0.26 & 0.14 & 0.11 & 0.09 & 0.06 & 0.04 & 0.04 & 0.03 & 0.03 & 0.02 & 0.02 & 0.01 \\
\hline $\mathrm{E}(+) / \mathrm{P}$ & 0.09 & 0.10 & 0.10 & 0.10 & 0.10 & 0.10 & 0.10 & 0.10 & 0.10 & 0.10 & 0.09 & 0.09 \\
\hline Firms & 772 & 189 & 236 & 170 & 144 & 140 & 128 & 125 & 119 & 114 & 60 & 64 \\
\hline
\end{tabular}


Table II-Continued

\begin{tabular}{|c|c|c|c|c|c|c|c|c|c|c|c|c|}
\hline & $1 \mathrm{~A}$ & 1B & 2 & 3 & 4 & 5 & 6 & 7 & 8 & 9 & $10 \mathrm{~A}$ & 10B \\
\hline \multicolumn{13}{|c|}{ Panel B: Portfolios Formed on Pre-Ranking $\beta$} \\
\hline Return & 1.20 & 1.20 & 1.32 & 1.26 & 1.31 & 1.30 & 1.30 & 1.23 & 1.23 & 1.33 & 1.34 & 1.18 \\
\hline$\beta$ & 0.81 & 0.79 & 0.92 & 1.04 & 1.13 & 1.19 & 1.26 & 1.32 & 1.41 & 1.52 & 1.63 & 1.73 \\
\hline $\ln (\mathrm{ME})$ & 4.21 & 4.86 & 4.75 & 4.68 & 4.59 & 4.48 & 4.36 & 4.25 & 3.97 & 3.78 & 3.52 & 3.15 \\
\hline $\ln (\mathrm{BE} / \mathrm{ME})$ & -0.18 & -0.13 & -0.22 & -0.21 & -0.23 & -0.22 & -0.22 & -0.25 & -0.23 & -0.27 & -0.31 & -0.50 \\
\hline $\ln (\mathrm{A} / \mathrm{ME})$ & 0.60 & 0.66 & 0.49 & 0.45 & 0.42 & 0.42 & 0.45 & 0.42 & 0.47 & 0.46 & 0.46 & 0.31 \\
\hline $\ln (\mathrm{A} / \mathrm{BE})$ & 0.78 & 0.79 & 0.71 & 0.66 & 0.64 & 0.65 & 0.67 & 0.67 & 0.70 & 0.73 & 0.77 & 0.81 \\
\hline $\mathrm{E} / \mathrm{P}$ dummy & 0.12 & 0.06 & 0.09 & 0.09 & 0.08 & 0.09 & 0.10 & 0.12 & 0.12 & 0.14 & 0.17 & 0.23 \\
\hline $\mathrm{E}(+) / \mathrm{P}$ & 0.11 & 0.12 & 0.10 & 0.10 & 0.10 & 0.10 & 0.10 & 0.09 & 0.10 & 0.09 & 0.09 & 0.08 \\
\hline Firms & 116 & 80 & 185 & 181 & 179 & 182 & 185 & 205 & 227 & 267 & 165 & 291 \\
\hline
\end{tabular}


for variation in $\beta$ that is unrelated to size, the relation between $\beta$ and average return is flat, even when $\beta$ is the only explanatory variable.

\section{B. Fama-MacBeth Regressions}

Table III shows time-series averages of the slopes from the month-by-month Fama-MacBeth (FM) regressions of the cross-section of stock returns on size, $\beta$, and the other variables (leverage, $\mathrm{E} / \mathrm{P}$, and book-to-market equity) used to explain average returns. The average slopes provide standard FM tests for determining which explanatory variables on average have non-zero expected premiums during the July 1963 to December 1990 period.

Like the average returns in Tables I and II, the regressions in Table III say that size, $\ln (\mathrm{ME})$, helps explain the cross-section of average stock returns. The average slope from the monthly regressions of returns on size alone is $-0.15 \%$, with a $t$-statistic of -2.58 . This reliable negative relation persists no matter which other explanatory variables are in the regressions; the average slopes on $\ln (\mathrm{ME})$ are always close to or more than 2 standard errors from 0 . The size effect (smaller stocks have higher average returns) is thus robust in the 1963-1990 returns on NYSE, AMEX, and NASDAQ stocks.

In contrast to the consistent explanatory power of size, the FM regressions show that market $\beta$ does not help explain average stock returns for 1963-1990. In a shot straight at the heart of the SLB model, the average slope from the regressions of returns on $\beta$ alone in Table III is $0.15 \%$ per month and only 0.46 standard errors from 0 . In the regressions of returns on size and $\beta$, size has explanatory power (an average slope -3.41 standard errors from 0 ), but the average slope for $\beta$ is negative and only 1.21 standard errors from 0. Lakonishok and Shapiro (1986) get similar results for NYSE stocks for 1962-1981. We can also report that $\beta$ shows no power to explain average returns (the average slopes are typically less than 1 standard error from 0 ) in FM regressions that use various combinations of $\beta$ with size, book-to-market equity, leverage, and $\mathrm{E} / \mathrm{P}$.

\section{Can $\beta$ Be Saved?}

What explains the poor results for $\beta$ ? One possibility is that other explanatory variables are correlated with true $\beta \mathrm{s}$, and this obscures the relation between average returns and measured $\beta$ s. But this line of attack cannot explain why $\beta$ has no power when used alone to explain average returns. Moreover, leverage, book-to-market equity, and $\mathrm{E} / \mathrm{P}$ do not seem to be good proxies for $\beta$. The averages of the monthly cross-sectional correlations between $\beta$ and the values of these variables for individual stocks are all within 0.15 of 0 .

Another hypothesis is that, as predicted by the SLB model, there is a positive relation between $\beta$ and average return, but the relation is obscured by noise in the $\beta$ estimates. However, our full-period post-ranking $\beta$ s do not seem to be imprecise. Most of the standard errors of the $\beta$ s (not shown) are 


\section{Table III}

\section{Average Slopes ( $t$-Statistics) from Month-by-Month Regressions of Stock Returns on $\beta$, Size, Book-to-Market Equity, Leverage, and $\mathbf{E} / \mathbf{P}$ : July 1963 to December 1990}

Stocks are assigned the post-ranking $\beta$ of the size- $\beta$ portfolio they are in at the end of June of year $t$ (Table I). BE is the book value of common equity plus balance-sheet deferred taxes, $\mathrm{A}$ is total book assets, and $\mathrm{E}$ is earnings (income before extraordinary items, plus income-statement deferred taxes, minus preferred dividends). BE, A, and $\mathrm{E}$ are for each firm's latest fiscal year ending in calendar year $t-1$. The accounting ratios are measured using market equity ME in December of year $t-1$. Firm size $\ln (\mathrm{ME})$ is measured in June of year $t$. In the regressions, these values of the explanatory variables for individual stocks are matched with CRSP returns for the months from July of year $t$ to June of year $t+1$. The gap between the accounting data and the returns ensures that the accounting data are available prior to the returns. If earnings are positive, $\mathrm{E}(+) / \mathrm{P}$ is the ratio of total earnings to market equity and $\mathrm{E} / \mathrm{P}$ dummy is 0 . If earnings are negative, $\mathrm{E}(+) / \mathrm{P}$ is 0 and $\mathrm{E} / \mathrm{P}$ dummy is 1 .

The average slope is the time-series average of the monthly regression slopes for July 1963 to December 1990, and the $t$-statistic is the average slope divided by its time-series standard error.

On average, there are 2267 stocks in the monthly regressions. To avoid giving extreme observations heavy weight in the regressions, the smallest and largest $0.5 \%$ of the observations on $\mathrm{E}(+) / \mathrm{P}, \mathrm{BE} / \mathrm{ME}, \mathrm{A} / \mathrm{ME}$, and $\mathrm{A} / \mathrm{BE}$ are set equal to the next largest or smallest values of the ratios (the 0.005 and 0.995 fractiles). This has no effect on inferences.

\begin{tabular}{|c|c|c|c|c|c|c|}
\hline$\beta$ & $\ln (\mathrm{ME})$ & $\ln (\mathrm{BE} / \mathrm{ME})$ & $\ln (\mathrm{A} / \mathrm{ME})$ & $\ln (\mathrm{A} / \mathrm{BE})$ & $\begin{array}{c}\mathrm{E} / \mathrm{P} \\
\text { Dummy }\end{array}$ & $\mathrm{E}(+) / \mathrm{P}$ \\
\hline \multicolumn{7}{|l|}{$\begin{array}{c}0.15 \\
(0.46)\end{array}$} \\
\hline & $\begin{array}{c}-0.15 \\
(-2.58)\end{array}$ & & & & & \\
\hline \multirow[t]{9}{*}{$\begin{array}{l}-0.37 \\
(-1.21)\end{array}$} & $\begin{array}{c}-0.17 \\
(-3.41)\end{array}$ & & & & & \\
\hline & & $\begin{array}{c}0.50 \\
(5.71)\end{array}$ & & & & \\
\hline & & & $\begin{array}{c}0.50 \\
(5.69)\end{array}$ & $\begin{array}{c}-0.57 \\
(-5.34)\end{array}$ & & \\
\hline & & & & & $\begin{array}{c}0.57 \\
(2.28)\end{array}$ & $\begin{array}{c}4.72 \\
(4.57)\end{array}$ \\
\hline & $\begin{array}{c}-0.11 \\
(-1.99)\end{array}$ & $\begin{array}{c}0.35 \\
(4.44)\end{array}$ & & & & \\
\hline & $\begin{array}{l}-0.11 \\
(-2.06)\end{array}$ & & $\begin{array}{c}0.35 \\
(4.32)\end{array}$ & $\begin{array}{l}-0.50 \\
(-4.56)\end{array}$ & & \\
\hline & $\begin{array}{l}-0.16 \\
(-3.06)\end{array}$ & & & & $\begin{array}{c}0.06 \\
(0.38)\end{array}$ & $\begin{array}{c}2.99 \\
(3.04)\end{array}$ \\
\hline & $\begin{array}{l}-0.13 \\
(-2.47)\end{array}$ & $\begin{array}{c}0.33 \\
(4.46)\end{array}$ & & & $\begin{array}{c}-0.14 \\
(-0.90)\end{array}$ & $\begin{array}{c}0.87 \\
(1.23)\end{array}$ \\
\hline & $\begin{array}{c}-0.13 \\
(-2.47)\end{array}$ & & $\begin{array}{c}0.32 \\
(4.28)\end{array}$ & $\begin{array}{c}-0.46 \\
(-4.45)\end{array}$ & $\begin{array}{l}-0.08 \\
(-0.56)\end{array}$ & $\begin{array}{c}1.15 \\
(1.57)\end{array}$ \\
\hline
\end{tabular}


0.05 or less, only 1 is greater than 0.1 , and the standard errors are small relative to the range of the $\beta$ s $(0.53$ to 1.79$)$.

The $\beta$-sorted portfolios in Tables I and II also provide strong evidence against the $\beta$-measurement-error story. When portfolios are formed on preranking $\beta$ s alone (Table II), the post-ranking $\beta$ s for the portfolios almost perfectly reproduce the ordering of the pre-ranking $\beta \mathrm{s}$. Only the $\beta$ for portfolio $1 \mathrm{~B}$ is out of line, and only by 0.02 . Similarly, when portfolios are formed on size and then pre-ranking $\beta \mathrm{s}$ (Table I), the post-ranking $\beta \mathrm{s}$ in each size decile closely reproduce the ordering of the pre-ranking $\beta \mathrm{s}$.

The correspondence between the ordering of the pre-ranking and postranking $\beta \mathrm{s}$ for the $\beta$-sorted portfolios in Tables I and II is evidence that the post-ranking $\beta \mathrm{s}$ are informative about the ordering of the true $\beta \mathrm{s}$. The problem for the SLB model is that there is no similar ordering in the average returns on the $\beta$-sorted portfolios. Whether one looks at portfolios sorted on $\beta$ alone (Table II) or on size and then $\beta$ (Table I), average returns are flat (Table II) or decline slightly (Table. I) as the post-ranking $\beta$ s increase.

Our evidence on the robustness of the size effect and the absence of a relation between $\beta$ and average return is so contrary to the SLB model that it behooves us to examine whether the results are special to 1963-1990. The appendix shows that NYSE returns for 1941-1990 behave like the NYSE, AMEX, and NASDAQ returns for 1963-1990; there is a reliable size effect over the full 50-year period, but little relation between $\beta$ and average return. Interestingly, there is a reliable simple relation between $\beta$ and average return during the 1941-1965 period. These 25 years are a major part of the samples in the early studies of the SLB model of Black, Jensen, and Scholes (1972) and Fama and MacBeth (1973). Even for the 1941-1965 period, however, the relation between $\beta$ and average return disappears when we control for size.

\section{Book-to-Market Equity, E/P, and Leverage}

Tables I to III say that there is a strong relation between the average returns on stocks and size, but there is no reliable relation between average returns and $\beta$. In this section we show that there is also a strong crosssectional relation between average returns and book-to-market equity. If anything, this book-to-market effect is more powerful than the size effect. We also find that the combination of size and book-to-market equity absorbs the apparent roles of leverage and $\mathrm{E} / \mathrm{P}$ in average stock returns.

\section{A. Average Returns}

Table IV shows average returns for July 1963 to December 1990 for portfolios formed on ranked values of book-to-market equity (BE/ME) or earnings-price ratio $(\mathrm{E} / \mathrm{P})$. The $\mathrm{BE} / \mathrm{ME}$ and $\mathrm{E} / \mathrm{P}$ portfolios in Table IV are formed in the same general way (one-dimensional yearly sorts) as the size and $\beta$ portfolios in Table II. (See the tables for details.) 
The relation between average return and $\mathrm{E} / \mathrm{P}$ has a familiar U-shape (e.g., Jaffe, Keim, and Westerfield (1989) for U.S. data, and Chan, Hamao, and Lakonishok (1991) for Japan). Average returns decline from $1.46 \%$ per month for the negative $\mathrm{E} / \mathrm{P}$ portfolio to $0.93 \%$ for the firms in portfolio $1 \mathrm{~B}$ that have low but positive E/P. Average returns then increase monotonically, reaching $1.72 \%$ per month for the highest $\mathrm{E} / \mathrm{P}$ portfolio.

The more striking evidence in Table IV is the strong positive relation between average return and book-to-market equity. Average returns rise from $0.30 \%$ for the lowest $\mathrm{BE} / \mathrm{ME}$ portfolio to $1.83 \%$ for the highest, a difference of $1.53 \%$ per month. This spread is twice as large as the difference of $0.74 \%$ between the average monthly returns on the smallest and largest size portfolios in Table II. Note also that the strong relation between book-tomarket equity and average return is unlikely to be a $\beta$ effect in disguise; Table IV shows that post-ranking market $\beta$ s vary little across portfolios formed on ranked values of $\mathrm{BE} / \mathrm{ME}$.

On average, only about 50 (out of 2317) firms per year have negative book equity, BE. The negative BE firms are mostly concentrated in the last 14 years of the sample, 1976-1989, and we do not include them in the tests. We can report, however, that average returns for negative $\mathrm{BE}$ firms are high, like the average returns of high $\mathrm{BE} / \mathrm{ME}$ firms. Negative $\mathrm{BE}$ (which results from persistently negative earnings) and high $\mathrm{BE} / \mathrm{ME}$ (which typically means that stock prices have fallen) are both signals of poor earning prospects. The similar average returns of negative and high $\mathrm{BE} / \mathrm{ME}$ firms are thus consistent with the hypothesis that book-to-market equity captures cross-sectional variation in average returns that is related to relative distress.

\section{B. Fama-MacBeth Regressions}

\section{B.1. $B E / M E$}

The FM regressions in Table III confirm the importance of book-to-market equity in explaining the cross-section of average stock returns. The average slope from the monthly regressions of returns on $\ln (\mathrm{BE} / \mathrm{ME})$ alone is $0.50 \%$, with a $t$-statistic of 5.71. This book-to-market relation is stronger than the size effect, which produces a $t$-statistic of -2.58 in the regressions of returns on $\ln (\mathrm{ME})$ alone. But book-to-market equity does not replace size in explaining average returns. When both $\ln (\mathrm{ME})$ and $\ln (\mathrm{BE} / \mathrm{ME})$ are included in the regressions, the average size slope is still -1.99 standard errors from 0 ; the book-to-market slope is an impressive 4.44 standard errors from 0.

\section{B.2. Leverage}

The FM regressions that explain returns with leverage variables provide interesting insight into the relation between book-to-market equity and average return. We use two leverage variables, the ratio of book assets to market equity, $\mathrm{A} / \mathrm{ME}$, and the ratio of book assets to book equity, $\mathrm{A} / \mathrm{BE}$. We interpret $\mathrm{A} / \mathrm{ME}$ as a measure of market leverage, while $\mathrm{A} / \mathrm{BE}$ is a measure 
Table IV

Properties of Portfolios Formed on Book-to-Market Equity (BE/ME) and Earnings-Price Ratio (E/P):

July 1963 to December 1990

At the end of each year $t-1,12$ portfolios are formed on the basis of ranked values of $\mathrm{BE} / \mathrm{ME}$ or $\mathrm{E} / \mathrm{P}$. Portfolios $2-9$ cover deciles of the ranking variables. The bottom and top 2 portfolios $(1 \mathrm{~A}, 1 \mathrm{~B}, 10 \mathrm{~A}$, and $10 \mathrm{~B})$ split the bottom and top deciles in half. For $\mathrm{E} / \mathrm{P}$, there are 13 portfolios; portfolio 0 is stocks with negative $\mathrm{E} / \mathrm{P}$. Since $\mathrm{BE} / \mathrm{ME}$ and $\mathrm{E} / \mathrm{P}$ are not strongly related to exchange listing, their portfolio breakpoints are determined on the basis of the ranked values of the variables for all stocks that satisfy the CRSP-COMPUSTAT data requirements. BE is the book value of common equity plus balance-sheet deferred taxes, $\mathrm{A}$ is total book assets, and $\mathrm{E}$ is earnings (income before extraordinary items, plus income-statement deferred taxes, minus preferred dividends). BE, A, and $\mathrm{E}$ are for each firm's latest fiscal year ending in calendar year $t-1$. The accounting ratios are measured using market equity ME in December of year $t-1$. Firm size $\ln (\mathrm{ME})$ is measured in June of year $t$, with ME denominated in millions of dollars. We calculate each portfolio's monthly equal-weighted return for July of year $t$ to June of year $t+1$, and then reform the portfolios at the end of year $t$.

Return is the time-series average of the monthly equal-weighted portfolio returns (in percent). $\ln (\mathrm{ME}), \ln (\mathrm{BE} / \mathrm{ME}), \ln (\mathrm{A} / \mathrm{ME}), \ln (\mathrm{A} / \mathrm{BE}), \mathrm{E}(+) / \mathrm{P}$ and $\mathrm{E} / \mathrm{P}$ dummy are the time-series averages of the monthly average values of these variables in each portfolio. Since the $\mathrm{E} / \mathrm{P}$ dummy is 0 when earnings are positive, and 1 when earnings are negative, $\mathrm{E} / \mathrm{P}$ dummy gives the average proportion of stocks with negative earnings in each portfolio.

$\beta$ is the time-series average of the monthly portfolio $\beta$ s. Stocks are assigned the post-ranking $\beta$ of the size- $\beta$ portfolio they are in at the end of June of year $t$ (Table I). These individual-firm $\beta \mathrm{s}$ are averaged to compute the monthly $\beta \mathrm{s}$ for each portfolio for July of year $t$ to June of year $t+1$.

Firms is the average number of stocks in the portfolio each month.

\begin{tabular}{|c|c|c|c|c|c|c|c|c|c|c|c|c|c|}
\hline Portfolio & 0 & $1 \mathrm{~A}$ & $1 \mathrm{~B}$ & 2 & 3 & 4 & 5 & 6 & 7 & 8 & 9 & $10 \mathrm{~A}$ & $10 \mathrm{~B}$ \\
\hline \multicolumn{14}{|c|}{ Panel A: Stocks Sorted on Book-to-Market Equity (BE/ME) } \\
\hline Return & & 0.30 & 0.67 & 0.87 & 0.97 & 1.04 & 1.17 & 1.30 & 1.44 & 1.50 & 1.59 & 1.92 & 1.83 \\
\hline$\beta$ & & 1.36 & 1.34 & 1.32 & 1.30 & 1.28 & 1.27 & 1.27 & 1.27 & 1.27 & 1.29 & 1.33 & 1.35 \\
\hline $\ln (\mathrm{ME})$ & & 4.53 & 4.67 & 4.69 & 4.56 & 4.47 & 4.38 & 4.23 & 4.06 & 3.85 & 3.51 & 3.06 & 2.65 \\
\hline $\ln (\mathrm{BE} / \mathrm{ME})$ & & -2.22 & -1.51 & -1.09 & -0.75 & -0.51 & -0.32 & -0.14 & 0.03 & 0.21 & 0.42 & 0.66 & 1.02 \\
\hline $\ln (\mathrm{A} / \mathrm{ME})$ & & -1.24 & -0.79 & -0.40 & -0.05 & 0.20 & 0.40 & 0.56 & 0.71 & 0.91 & 1.12 & 1.35 & 1.75 \\
\hline $\ln (\mathrm{A} / \mathrm{BE})$ & & 0.94 & 0.71 & 0.68 & 0.70 & 0.71 & 0.71 & 0.70 & 0.68 & 0.70 & 0.70 & 0.70 & 0.73 \\
\hline $\mathrm{E} / \mathrm{P}$ dummy & & 0.29 & 0.15 & 0.10 & 0.08 & 0.08 & 0.08 & 0.09 & 0.09 & 0.11 & 0.15 & 0.22 & 0.36 \\
\hline $\mathrm{E}(+) / \mathrm{P}$ & & 0.03 & 0.04 & 0.06 & 0.08 & 0.09 & 0.10 & 0.11 & 0.11 & 0.12 & 0.12 & 0.11 & 0.10 \\
\hline Firms & & 89 & 98 & 209 & 222 & 226 & 230 & 235 & 237 & 239 & 239 & 120 & 117 \\
\hline
\end{tabular}


Table IV-Continued

\begin{tabular}{lrrrrrrrrrrrrr}
\hline Portfolio & 0 & $1 \mathrm{~A}$ & \multicolumn{1}{c}{ 1B } & \multicolumn{1}{c}{2} & 3 & 4 & 5 & 6 & 7 & 8 & 9 & $10 \mathrm{~A}$ & $10 \mathrm{~B}$ \\
\hline & & \multicolumn{7}{c}{ Panel B: Stocks Sorted on Earnings-Price Ratio (E/P) } \\
\hline Return & 1.46 & 1.04 & 0.93 & 0.94 & 1.03 & 1.18 & 1.22 & 1.33 & 1.42 & 1.46 & 1.57 & 1.74 & 1.72 \\
$\beta$ & 1.47 & 1.40 & 1.35 & 1.31 & 1.28 & 1.26 & 1.25 & 1.26 & 1.24 & 1.23 & 1.24 & 1.28 & 1.31 \\
$\ln (\mathrm{ME})$ & 2.48 & 3.64 & 4.33 & 4.61 & 4.64 & 4.63 & 4.58 & 4.49 & 4.37 & 4.28 & 4.07 & 3.82 & 3.52 \\
$\ln (\mathrm{BE} / \mathrm{ME})$ & -0.10 & -0.76 & -0.91 & -0.79 & -0.61 & -0.47 & -0.33 & -0.21 & -0.08 & 0.02 & 0.15 & 0.26 & 0.40 \\
$\ln (\mathrm{A} / \mathrm{ME})$ & 0.90 & -0.05 & -0.27 & -0.16 & 0.03 & 0.18 & 0.31 & 0.44 & 0.58 & 0.70 & 0.85 & 1.01 & 1.25 \\
$\ln (\mathrm{A} / \mathrm{BE})$ & 0.99 & 0.70 & 0.63 & 0.63 & 0.64 & 0.65 & 0.64 & 0.65 & 0.66 & 0.68 & 0.71 & 0.75 & 0.86 \\
E/P dummy & 1.00 & 0.00 & 0.00 & 0.00 & 0.00 & 0.00 & 0.00 & 0.00 & 0.00 & 0.00 & 0.00 & 0.00 & 0.00 \\
E(+)/P & 0.00 & 0.01 & 0.03 & 0.05 & 0.06 & 0.08 & 0.09 & 0.11 & 0.12 & 0.14 & 0.16 & 0.20 & 0.28 \\
Firms & 355 & 88 & 90 & 182 & 190 & 193 & 196 & 194 & 197 & 195 & 195 & 95 & 91 \\
\hline
\end{tabular}


of book leverage. The regressions use the natural logs of the leverage ratios, $\ln (\mathrm{A} / \mathrm{ME})$ and $\ln (\mathrm{A} / \mathrm{BE})$, because preliminary tests indicated that logs are a good functional form for capturing leverage effects in average returns. Using logs also leads to a simple interpretation of the relation between the roles of leverage and book-to-market equity in average returns.

The FM regressions of returns on the leverage variables (Table III) pose a bit of a puzzle. The two leverage variables are related to average returns, but with opposite signs. As in Bhandari (1988), higher market leverage is associated with higher average returns; the average slopes for $\ln (\mathrm{A} / \mathrm{ME})$ are always positive and more than 4 standard errors from 0 . But higher book leverage is associated with lower average returns; the average slopes for $\ln (\mathrm{A} / \mathrm{BE})$ are always negative and more than 4 standard errors from 0.

The puzzle of the opposite slopes on $\ln (\mathrm{A} / \mathrm{ME})$ and $\ln (\mathrm{A} / \mathrm{BE})$ has a simple solution. The average slopes for the two leverage variables are opposite in sign but close in absolute value, e.g., 0.50 and -0.57 . Thus it is the difference between market and book leverage that helps explain average returns. But the difference between market and book leverage is book-tomarket equity, $\ln (\mathrm{BE} / \mathrm{ME})=\ln (\mathrm{A} / \mathrm{ME})-\ln (\mathrm{A} / \mathrm{BE})$. Table III shows that the average book-to-market slopes in the FM regressions are indeed close in absolute value to the slopes for the two leverage variables.

The close links between the leverage and book-to-market results suggest that there are two equivalent ways to interpret the book-to-market effect in average returns. A high ratio of book equity to market equity (a low stock price relative to book value) says that the market judges the prospects of a firm to be poor relative to firms with low $\mathrm{BE} / \mathrm{ME}$. Thus $\mathrm{BE} / \mathrm{ME}$ may capture the relative-distress effect postulated by Chan and Chen (1991). A high book-to-market ratio also says that a firm's market leverage is high relative to its book leverage; the firm has a large amount of market-imposed leverage because the market judges that its prospects are poor and discounts its stock price relative to book value. In short, our tests suggest that the relativedistress effect, captured by $\mathrm{BE} / \mathrm{ME}$, can also be interpreted as an involuntary leverage effect, which is captured by the difference between $\mathrm{A} / \mathrm{ME}$ and $\mathrm{A} / \mathrm{BE}$.

\section{B.3. $E / P$}

Ball (1978) posits that the earnings-price ratio is a catch-all for omitted risk factors in expected returns. If current earnings proxy for expected future earnings, high-risk stocks with high expected returns will have low prices relative to their earnings. Thus, $\mathrm{E} / \mathrm{P}$ should be related to expected returns, whatever the omitted sources of risk. This argument only makes sense, however, for firms with positive earnings. When current earnings are negative, they are not a proxy for the earnings forecasts embedded in the stock price, and $\mathrm{E} / \mathrm{P}$ is not a proxy for expected returns. Thus, the slope for $\mathrm{E} / \mathrm{P}$ in the FM regressions is based on positive values; we use a dummy variable for $\mathrm{E} / \mathrm{P}$ when earnings are negative. 
The U-shaped relation between average return and $\mathrm{E} / \mathrm{P}$ observed in Table IV is also apparent when the $\mathrm{E} / \mathrm{P}$ variables are used alone in the FM regressions in Table III. The average slope on the $\mathrm{E} / \mathrm{P}$ dummy variable (0.57\% per month, 2.28 standard errors from 0 ) confirms that firms with negative earnings have higher average returns. The average slope for stocks with positive $\mathrm{E} / \mathrm{P}$ (4.72\% per month, 4.57 standard errors from 0$)$ shows that average returns increase with $\mathrm{E} / \mathrm{P}$ when it is positive.

Adding size to the regressions kills the explanatory power of the $\mathrm{E} / \mathrm{P}$ dummy. Thus the high average returns of negative $\mathrm{E} / \mathrm{P}$ stocks are better captured by their size, which Table IV says is on average small. Adding both size and book-to-market equity to the $\mathrm{E} / \mathrm{P}$ regressions kills the $\mathrm{E} / \mathrm{P}$ dummy and lowers the average slope on $\mathrm{E} / \mathrm{P}$ from 4.72 to $0.87(t=1.23)$. In contrast, the average slopes for $\ln (\mathrm{ME})$ and $\ln (\mathrm{BE} / \mathrm{ME})$ in the regressions that include $\mathrm{E} / \mathrm{P}$ are similar to those in the regressions that explain average returns with only size and book-to-market equity. The results suggest that most of the relation between (positive) $\mathrm{E} / \mathrm{P}$ and average return is due to the positive correlation between $\mathrm{E} / \mathrm{P}$ and $\ln (\mathrm{BE} / \mathrm{ME})$, illustrated in Table IV; firms with high $\mathrm{E} / \mathrm{P}$ tend to have high book-to-market equity ratios.

\section{A Parsimonious Model for Average Returns}

The results to here are easily summarized:

(1) When we allow for variation in $\beta$ that is unrelated to size, there is no reliable relation between $\beta$ and average return.

(2) The opposite roles of market leverage and book leverage in average returns are captured well by book-to-market equity.

(3) The relation between $\mathrm{E} / \mathrm{P}$ and average return seems to be absorbed by the combination of size and book-to-market equity.

In a nutshell, market $\beta$ seems to have no role in explaining the average returns on NYSE, AMEX, and NASDAQ stocks for 1963-1990, while size and book-to-market equity capture the cross-sectional variation in average stock returns that is related to leverage and $\mathrm{E} / \mathrm{P}$.

\section{A. Average Returns, Size and Book-to-Market Equity}

The average return matrix in Table $\mathrm{V}$ gives a simple picture of the two-dimensional variation in average returns that results when the 10 size deciles are each subdivided into 10 portfolios based on ranked values of $\mathrm{BE} / \mathrm{ME}$ for individual stocks. Within a size decile (across a row of the average return matrix), returns typically increase strongly with $\mathrm{BE} / \mathrm{ME}$ : on average, the returns on the lowest and highest $\mathrm{BE} / \mathrm{ME}$ portfolios in a size decile differ by $0.99 \%(1.63 \%-0.64 \%)$ per month. Similarly, looking down the columns of the average return matrix shows that there is a negative relation between average return and size: on average, the spread of returns across the size portfolios in a $\mathrm{BE} / \mathrm{ME}$ group is $0.58 \%$ per month. The average return matrix gives life to the conclusion from the regressions that, 
Table V

\section{Average Monthly Returns on Portfolios Formed on Size and Book-to-Market Equity; Stocks Sorted by ME (Down) and then BE/ME (Across): July 1963 to December 1990}

In June of each year $t$, the NYSE, AMEX, and NASDAQ stocks that meet the CRSPCOMPUSTAT data requirements are allocated to 10 size portfolios using the NYSE size (ME) breakpoints. The NYSE, AMEX, and NASDAQ stocks in each size decile are then sorted into $10 \mathrm{BE} / \mathrm{ME}$ portfolios using the book-to-market ratios for year $t-1$. $\mathrm{BE} / \mathrm{ME}$ is the book value of common equity plus balance-sheet deferred taxes for fiscal year $t-1$, over market equity for December of year $t-1$. The equal-weighted monthly portfolio returns are then calculated for July of year $t$ to June of year $t+1$.

Average monthly return is the time-series average of the monthly equal-weighted portfolio returns (in percent).

The All column shows average returns for equal-weighted size decile portfolios. The All row shows average returns for equal-weighted portfolios of the stocks in each BE/ME group.

\begin{tabular}{lccccccccccc}
\hline & \multicolumn{10}{c}{ Book-to-Market Portfolios } \\
\cline { 2 - 12 } & All & Low & 2 & 3 & 4 & 5 & 6 & 7 & 8 & 9 & High \\
\hline All & 1.23 & 0.64 & 0.98 & 1.06 & 1.17 & 1.24 & 1.26 & 1.39 & 1.40 & 1.50 & 1.63 \\
Small-ME & 1.47 & 0.70 & 1.14 & 1.20 & 1.43 & 1.56 & 1.51 & 1.70 & 1.71 & 1.82 & 1.92 \\
ME-2 & 1.22 & 0.43 & 1.05 & 0.96 & 1.19 & 1.33 & 1.19 & 1.58 & 1.28 & 1.43 & 1.79 \\
ME-3 & 1.22 & 0.56 & 0.88 & 1.23 & 0.95 & 1.36 & 1.30 & 1.30 & 1.40 & 1.54 & 1.60 \\
ME-4 & 1.19 & 0.39 & 0.72 & 1.06 & 1.36 & 1.13 & 1.21 & 1.34 & 1.59 & 1.51 & 1.47 \\
ME-5 & 1.24 & 0.88 & 0.65 & 1.08 & 1.47 & 1.13 & 1.43 & 1.44 & 1.26 & 1.52 & 1.49 \\
ME-6 & 1.15 & 0.70 & 0.98 & 1.14 & 1.23 & 0.94 & 1.27 & 1.19 & 1.19 & 1.24 & 1.50 \\
ME-7 & 1.07 & 0.95 & 1.00 & 0.99 & 0.83 & 0.99 & 1.13 & 0.99 & 1.16 & 1.10 & 1.47 \\
ME-8 & 1.08 & 0.66 & 1.13 & 0.91 & 0.95 & 0.99 & 1.01 & 1.15 & 1.05 & 1.29 & 1.55 \\
ME-9 & 0.95 & 0.44 & 0.89 & 0.92 & 1.00 & 1.05 & 0.93 & 0.82 & 1.11 & 1.04 & 1.22 \\
Large-ME & 0.89 & 0.93 & 0.88 & 0.84 & 0.71 & 0.79 & 0.83 & 0.81 & 0.96 & 0.97 & 1.18 \\
\hline
\end{tabular}

controlling for size, book-to-market equity captures strong variation in average returns, and controlling for book-to-market equity leaves a size effect in average returns.

\section{B. The Interaction between Size and Book-to-Market Equity}

The average of the monthly correlations between the cross-sections of $\ln (\mathrm{ME})$ and $\ln (\mathrm{BE} / \mathrm{ME})$ for individual stocks is -0.26 . The negative correlation is also apparent in the average values of $\ln (\mathrm{ME})$ and $\ln (\mathrm{BE} / \mathrm{ME})$ for the portfolios sorted on $\mathrm{ME}$ or BE/ME in Tables II and IV. Thus, firms with low market equity are more likely to have poor prospects, resulting in low stock prices and high book-to-market equity. Conversely, large stocks are more likely to be firms with stronger prospects, higher stock prices, lower book-tomarket equity, and lower average stock returns.

The correlation between size and book-to-market equity affects the regressions in Table III. Including $\ln (\mathrm{BE} / \mathrm{ME})$ moves the average slope on $\ln (\mathrm{ME})$ from $-0.15(t=-2.58)$ in the univariate regressions to $-0.11(t=-1.99)$ in the bivariate regressions. Similarly, including $\ln (\mathrm{ME})$ in the regressions 
lowers the average slope on $\ln (\mathrm{BE} / \mathrm{ME})$ from 0.50 to 0.35 (still a healthy 4.44 standard errors from 0 ). Thus, part of the size effect in the simple regressions is due to the fact that small ME stocks are more likely to have high book-to-market ratios, and part of the simple book-to-market effect is due to the fact that high $\mathrm{BE} / \mathrm{ME}$ stocks tend to be small (they have low ME).

We should not, however, exaggerate the links between size and book-tomarket equity. The correlation $(-0.26)$ between $\ln (\mathrm{ME})$ and $\ln (\mathrm{BE} / \mathrm{ME})$ is not extreme, and the average slopes in the bivariate regressions in Table III show that $\ln (\mathrm{ME})$ and $\ln (\mathrm{BE} / \mathrm{ME})$ are both needed to explain the cross-section of average returns. Finally, the $10 \times 10$ average return matrix in Table V provides concrete evidence that, (a) controlling for size, book-to-market equity captures substantial variation in the cross-section of average returns, and (b) within $\mathrm{BE} / \mathrm{ME}$ groups average returns are related to size.

\section{Subperiod Averages of the FM Slopes}

The message from the average FM slopes for 1963-1990 (Table III) is that size on average has a negative premium in the cross-section of stock returns, book-to-market equity has a positive premium, and the average premium for market $\beta$ is essentially 0 . Table VI shows the average FM slopes for two roughly equal subperiods (July 1963-December 1976 and January 1977December 1990) from two regressions: (a) the cross-section of stock returns on size, $\ln (\mathrm{ME})$, and book-to-market equity, $\ln (\mathrm{BE} / \mathrm{ME})$, and (b) returns on $\beta$, $\ln (\mathrm{ME})$, and $\ln (\mathrm{BE} / \mathrm{ME})$. For perspective, average returns on the valueweighted and equal-weighted (VW and EW) portfolios of NYSE stocks are also shown.

In FM regressions, the intercept is the return on a standard portfolio (the weights on stocks sum to 1 ) in which the weighted averages of the explanatory variables are 0 (Fama (1976), chapter 9). In our tests, the intercept is weighted toward small stocks (ME is in millions of dollars so $\ln (\mathrm{ME})=0$ implies $\mathrm{ME}=\$ 1$ million) and toward stocks with relatively high book-tomarket ratios (Table IV says that $\ln (\mathrm{BE} / \mathrm{ME})$ is negative for the typical firm, so $\ln (\mathrm{BE} / \mathrm{ME})=0$ is toward the high end of the sample ratios). Thus it is not surprising that the average intercepts are always large relative to their standard errors and relative to the returns on the NYSE VW and EW portfolios.

Like the overall period, the subperiods do not offer much hope that the average premium for $\beta$ is economically important. The average FM slope for $\beta$ is only slightly positive for $1963-1976(0.10 \%$ per month, $t=0.25)$, and it is negative for 1977-1990 ( $-0.44 \%$ per month, $t=-1.17)$. There is a hint that the size effect is weaker in the 1977-1990 period, but inferences about the average size slopes for the subperiods lack power.

Unlike the size effect, the relation between book-to-market equity and average return is so strong that it shows up reliably in both the 1963-1976 and the 1977-1990 subperiods. The average slopes for $\ln (\mathrm{BE} / \mathrm{ME})$ are all more than 2.95 standard errors from 0 , and the average slopes for the 


\section{Table VI}

Subperiod Average Monthly Returns on the NYSE Equal-Weighted and Value-Weighted Portfolios and Subperiod Means of the Intercepts and Slopes from the Monthly FM Cross-Sectional Regressions of Returns on (a) Size $(\ln (\mathbf{M E}))$ and Book-to-Market Equity $(\ln (\mathrm{BE} / \mathrm{ME}))$, and $(\mathrm{b}) \beta, \ln (\mathrm{ME})$, and $\ln (\mathbf{B E} / \mathbf{M E})$

Mean is the time-series mean of a monthly return, Std is its time-series standard deviation, and $t(\mathrm{Mn})$ is Mean divided by its time-series standard error.

\begin{tabular}{|c|c|c|c|c|c|c|c|c|c|}
\hline \multirow[b]{2}{*}{ Variable } & \multicolumn{3}{|c|}{ 7/63-12/90 (330 Mos.) } & \multicolumn{3}{|c|}{ 7/63-12/76 (162 Mos.) } & \multicolumn{3}{|c|}{ 1/77-12/90 (168 Mos.) } \\
\hline & Mean & Std & $t(\mathrm{Mn})$ & Mean & Std & $t(\mathrm{Mn})$ & Mean & Std & $t(\mathrm{Mn})$ \\
\hline \multicolumn{10}{|c|}{ NYSE Value-Weighted (VW) and Equal-Weighted (EW) Portfolio Returns } \\
\hline VW & 0.81 & 4.47 & 3.27 & 0.56 & 4.26 & 1.67 & 1.04 & 4.66 & 2.89 \\
\hline EW & 0.97 & 5.49 & 3.19 & 0.77 & 5.70 & 1.72 & 1.15 & 5.28 & 2.82 \\
\hline \multicolumn{10}{|c|}{$R_{i t}=\mathrm{a}+\mathrm{b}_{2 t} \ln \left(\mathrm{ME}_{i t}\right)+\mathrm{b}_{3 t} \ln \left(\mathrm{BE} / \mathrm{ME}_{i t}\right)+e_{i t}$} \\
\hline a & 1.77 & 8.51 & 3.77 & 1.86 & 10.10 & 2.33 & 1.69 & 6.67 & 3.27 \\
\hline $\mathrm{b}_{2}$ & -0.11 & 1.02 & -1.99 & -0.16 & 1.25 & -1.62 & -0.07 & 0.73 & -1.16 \\
\hline $\mathrm{b}_{3}$ & 0.35 & 1.45 & 4.43 & 0.36 & 1.53 & 2.96 & 0.35 & 1.37 & 3.30 \\
\hline \multicolumn{10}{|c|}{$R_{i t}=\mathrm{a}+\mathrm{b}_{1 t} \beta_{i t}+\mathrm{b}_{2 t} \ln \left(\mathrm{ME}_{i t}\right)+\mathrm{b}_{3 t} \ln \left(\mathrm{BE} / \mathrm{ME}_{i t}\right)+e_{i t}$} \\
\hline a & 2.07 & 5.75 & 6.55 & 1.73 & 6.22 & 3.54 & 2.40 & 5.25 & 5.92 \\
\hline$b_{1}$ & -0.17 & 5.12 & -0.62 & 0.10 & 5.33 & 0.25 & -0.44 & 4.91 & -1.17 \\
\hline$b_{2}$ & -0.12 & 0.89 & -2.52 & -0.15 & 1.03 & -1.91 & -0.09 & 0.74 & -1.64 \\
\hline$b_{3}$ & 0.33 & 1.24 & 4.80 & 0.34 & 1.36 & 3.17 & 0.31 & 1.10 & 3.67 \\
\hline
\end{tabular}

subperiods $(0.36$ and 0.35$)$ are close to the average slope $(0.35)$ for the overall period. The subperiod results thus support the conclusion that, among the variables considered here, book-to-market equity is consistently the most powerful for explaining the cross-section of average stock returns.

Finally, Roll (1983) and Keim (1983) show that the size effect is stronger in January. We have examined the monthly slopes from the FM regressions in Table VI for evidence of a January seasonal in the relation between book-tomarket equity and average return. The average January slopes for $\ln (\mathrm{BE} / \mathrm{ME})$ are about twice those for February to December. Unlike the size effect, however, the strong relation between book-to-market equity and average return is not special to January. The average monthly February-to-December slopes for $\ln (\mathrm{BE} / \mathrm{ME})$ are about 4 standard errors from 0 , and they are close to (within 0.05 of) the average slopes for the whole year. Thus, there is a January seasonal in the book-to-market equity effect, but the positive relation between $\mathrm{BE} / \mathrm{ME}$ and average return is strong throughout the year.

\section{D. $\beta$ and the Market Factor: Caveats}

Some caveats about the negative evidence on the role of $\beta$ in average returns are in order. The average premiums for $\beta$, size, and book-to-market 
equity depend on the definitions of the variables used in the regressions. For example, suppose we replace book-to-market equity $(\ln (\mathrm{BE} / \mathrm{ME}))$ with book equity $(\ln (\mathrm{BE}))$. As long as size $(\ln (\mathrm{ME}))$ is also in the regression, this change will not affect the intercept, the fitted values or the $R^{2}$. But the change, in variables increases the average slope (and the $t$-statistic) on $\ln (\mathrm{ME})$. In other words, it increases the risk premium associated with size. Other redefinitions of the $\beta$, size, and book-to-market variables will produce different regression slopes and perhaps different inferences about average premiums, including possible resuscitation of a role for $\beta$. And, of course, at the moment, we have no theoretical basis for choosing among different versions of the variables.

Moreover, the tests here are restricted to stocks. It is possible that including other assets will change the inferences about the average premiums for $\beta$, size, and book-to-market equity. For example, the large average intercepts for the FM regressions in Table VI suggest that the regressions will not do a good job on Treasury bills, which have low average returns and are likely to have small loadings on the underlying market, size, and book-to-market factors in returns. Extending the tests to bills and other bonds may well change our inferences about average risk premiums, including the revival of a role for market $\beta$.

We emphasize, however, that different approaches to the tests are not likely to revive the Sharpe-Lintner-Black model. Resuscitation of the SLB model requires that a better proxy for the market portfolio (a) overturns our evidence that the simple relation between $\beta$ and average stock returns is flat and (b) leaves $\beta$ as the only variable relevant for explaining average returns. Such results seem unlikely, given Stambaugh's (1982) evidence that tests of the SLB model do not seem to be sensitive to the choice of a market proxy. Thus, if there is a role for $\beta$ in average returns, it is likely to be found in a multi-factor model that transforms the flat simple relation between average return and $\beta$ into a positively sloped conditional relation.

\section{Conclusions and Implications}

The Sharpe-Lintner-Black model has long shaped the way academics and practitioners think about average return and risk. Black, Jensen, and Scholes (1972) and Fama and MacBeth (1973) find that, as predicted by the model, there is a positive simple relation between average return and market $\beta$ during the early years (1926-1968) of the CRSP NYSE returns file. Like Reinganum (1981) and Lakonishok and Shapiro (1986), we find that this simple relation between $\beta$ and average return disappears during the more recent 1963-1990 period. The appendix that follows shows that the relation between $\beta$ and average return is also weak in the last half century (1941-1990) of returns on NYSE stocks. In short, our tests do not support the central prediction of the SLB model, that average stock returns are positively related to market $\beta$.

Banz (1981) documents a strong negative relation between average return and firm size. Bhandari (1988) finds that average return is positively related to leverage, and Basu (1983) finds a positive relation between average return 
and E/P. Stattman (1980) and Rosenberg, Reid, and Lanstein (1985) document a positive relation between average return and book-to-market equity for U.S. stocks, and Chan, Hamao, and Lakonishok (1992) find that BE/ME is also a powerful variable for explaining average returns on Japanese stocks.

Variables like size, E/P, leverage, and book-to-market equity are all scaled versions of a firm's stock price. They can be regarded as different ways of extracting information from stock prices about the cross-section of expected stock returns (Ball (1978); Keim (1988)). Since all these variables are scaled versions of price, it is reasonable to expect that some of them are redundant for explaining average returns. Our main result is that for the 1963-1990 period, size and book-to-market equity capture the cross-sectional variation in average stock returns associated with size, $\mathrm{E} / \mathrm{P}$, book-to-market equity, and leverage.

\section{A. Rational Asset-Pricing Stories}

Are our results consistent with asset-pricing theory? Since the FM intercept is constrained to be the same for all stocks, FM regressions always impose a linear factor structure on returns and expected returns that is consistent with the multifactor asset-pricing models of Merton (1973) and Ross (1976). Thus our tests impose a rational asset-pricing framework on the relation between average return and size and book-to-market equity.

Even if our results are consistent with asset-pricing theory, they are not economically satisfying. What is the economic explanation for the roles of size and book-to-market equity in average returns? We suggest several paths of inquiry.

(a) The intercepts and slopes in the monthly FM regressions of returns on $\ln (\mathrm{ME})$ and $\ln (\mathrm{BE} / \mathrm{ME})$ are returns on portfolios that mimic the underlying common risk factors in returns proxied by size and book-to-market equity (Fama (1976), chapter 9). Examining the relations between the returns on these portfolios and economic variables that measure variation in business conditions might help expose the nature of the economic risks captured by size and book-to-market equity.

(b) Chan, Chen, and Hsieh (1985) argue that the relation between size and average return proxies for a more fundamental relation between expected returns and economic risk factors. Their most powerful factor in explaining the size effect is the difference between the monthly returns on low- and high-grade corporate bonds, which in principle captures a kind of default risk in returns that is priced. It would be interesting to test whether loadings on this or other economic factors, such as those of Chen, Roll, and Ross (1986), can explain the roles of size and book-tomarket equity in our tests.

(c) In a similar vein, Chan and Chen (1991) argue that the relation between size and average return is a relative-prospects effect. The earning prospects of distressed firms are more sensitive to economic 
conditions. This results in a distress factor in returns that is priced in expected returns. Chan and Chen construct two mimicking portfolios for the distress factor, based on dividend changes and leverage. It would be interesting to check whether loadings on their distress factors absorb the size and book-to-market equity effects in average returns that are documented here.

(d) In fact, if stock prices are rational, $\mathrm{BE} / \mathrm{ME}$, the ratio of the book value of a stock to the market's assessment of its value, should be a direct indicator of the relative prospects of firms. For example, we expect that high $\mathrm{BE} / \mathrm{ME}$ firms have low earnings on assets relative to low $\mathrm{BE} / \mathrm{ME}$ firms. Our work (in progress) suggests that there is indeed a clean separation between high and low $\mathrm{BE} / \mathrm{ME}$ firms on various measures of economic fundamentals. Low $\mathrm{BE} / \mathrm{ME}$ firms are persistently strong performers, while the economic performance of high $\mathrm{BE} / \mathrm{ME}$ firms is persistently weak.

\section{B. Irrational Asset-Pricing Stories}

The discussion above assumes that the asset-pricing effects captured by size and book-to-market equity are rational. For BE/ME, our most powerful expected-return variable, there is an obvious alternative. The cross-section of book-to-market ratios might result from market overreaction to the relative prospects of firms. If overreaction tends to be corrected, $\mathrm{BE} / \mathrm{ME}$ will predict the cross-section of stock returns.

Simple tests do not confirm that the size and book-to-market effects in average returns are due to market overreaction, at least of the type posited by DeBondt and Thaler (1985). One overreaction measure used by DeBondt and Thaler is a stock's most recent 3-year return. Their overreaction story predicts that 3-year losers have strong post-ranking returns relative to 3-year winners. In FM regressions (not shown) for individual stocks, the 3-year lagged return shows no power even when used alone to explain average returns. The univariate average slope for the lagged return is negative, -6 basis points per month, but less than 0.5 standard errors from 0 .

\section{Applications}

Our main result is that two easily measured variables, size and book-tomarket equity, seem to describe the cross-section of average stock returns. Prescriptions for using this evidence depend on (a) whether it will persist, and (b) whether it results from rational or irrational asset-pricing.

It is possible that, by chance, size and book-to-market equity happen to describe the cross-section of average returns in our sample, but they were and are unrelated to expected returns. We put little weight on this possibility, especially for book-to-market equity. First, although BE/ME has long been touted as a measure of the return prospects of stocks, there is no evidence that its explanatory power deteriorates through time. The 1963-1990 relation between $\mathrm{BE} / \mathrm{ME}$ and average return is strong, and remarkably similar 
for the 1963-1976 and 1977-1990 subperiods. Second, our preliminary work on economic fundamentals suggests that high-BE/ME firms tend to be persistently poor earners relative to low-BE/ME firms. Similarly, small firms have a long period of poor earnings during the 1980s not shared with big firms. The systematic patterns in fundamentals give us some hope that size and book-to-market equity proxy for risk factors in returns, related to relative earning prospects, that are rationally priced in expected returns.

If our results are more than chance, they have practical implications for portfolio formation and performance evaluation by investors whose primary concern is long-term average returns. If asset-pricing is rational, size and $\mathrm{BE} / \mathrm{ME}$ must proxy for risk. Our results then imply that the performance of managed portfolios (e.g., pension funds and mutual funds) can be evaluated by comparing their average returns with the average returns of benchmark portfolios with similar size and $\mathrm{BE} / \mathrm{ME}$ characteristics. Likewise, the expected returns for different portfolio strategies can be estimated from the historical average returns of portfolios with matching size and $\mathrm{BE} / \mathrm{ME}$ properties.

If asset-pricing is irrational and size and $\mathrm{BE} / \mathrm{ME}$ do not proxy for risk, our results might still be used to evaluate portfolio performance and measure the expected returns from alternative investment strategies. If stock prices are irrational, however, the likely persistence of the results is more suspect.

\section{Appendix \\ Size Versus $\beta$ : 1941-1990}

Our results on the absence of a relation between $\beta$ and average stock returns for 1963-1990 are so contrary to the tests of the Sharpe-Lintner-Black model by Black, Jensen, and Scholes (1972), Fama and MacBeth (1973), and (more recently) Chan and Chen (1988), that further tests are appropriate. We examine the roles of size and $\beta$ in the average returns on NYSE stocks for the half-century 1941-1990, the longest available period that avoids the high volatility of returns in the Great Depression. We do not include the accounting variables in the tests because of the strong selection bias (toward successful firms) in the COMPUSTAT data prior to 1962.

We first replicate the results of Chan and Chen (1988). Like them, we find that when portfolios are formed on size alone, there are strong relations between average return and either size or $\beta$; average return increases with $\beta$ and decreases with size. For size portfolios, however, size $(\ln (\mathrm{ME}))$ and $\beta$ are almost perfectly correlated $(-0.98)$, so it is difficult to distinguish between the roles of size and $\beta$ in average returns.

One way to generate strong variation in $\beta$ that is unrelated to size is to form portfolios on size and then on $\beta$. As in Tables I to III, we find that the resulting independent variation in $\beta$ just about washes out the positive simple relation between average return and $\beta$ observed when portfolios are formed on size alone. The results for NYSE stocks for 1941-1990 are thus much like those for NYSE, AMEX, and NASDAQ stocks for 1963-1990. 
This appendix also has methodological goals. For example, the FM regressions in Table III use returns on individual stocks as the dependent variable. Since we allocate portfolio $\beta \mathrm{s}$ to individual stocks but use firm-specific values of other variables like size, $\beta$ may be at a disadvantage in the regressions for individual stocks. This appendix shows, however, that regressions for portfolios, which put $\beta$ and size on equal footing, produce results comparable to those for individual stocks.

\section{A. Size Portfolios}

Table AI shows average monthly returns and market $\beta$ s for 12 portfolios of NYSE stocks formed on the basis of size (ME) at the end of each year from 1940 to 1989 . For these size portfolios, there is a strong positive relation between average return and $\beta$. Average returns fall from $1.96 \%$ per month for the smallest ME portfolio (1A) to $0.93 \%$ for the largest (10B) and $\beta$ falls from 1.60 to 0.95 . (Note also that, as claimed earlier, estimating $\beta$ as the sum of the slopes in the regression of a portfolio's return on the current and prior month's NYSE value-weighted return produces much larger $\beta$ s for the smallest ME portfolios and slightly smaller $\beta$ s for the largest ME portfolios.)

The FM regressions in Table AI confirm the positive simple relation between average return and $\beta$ for size portfolios. In the regressions of the size-portfolio returns on $\beta$ alone, the average premium for a unit of $\beta$ is $1.45 \%$ per month. In the regressions of individual stock returns on $\beta$ (where stocks are assigned the $\beta$ of their size portfolio), the premium for a unit of $\beta$ is $1.39 \%$. Both estimates are about 3 standard errors from 0 . Moreover, the $\beta \mathrm{s}$ of size portfolios do not leave a residual size effect; the average residuals from the simple regressions of returns on $\beta$ in Table AI show no relation to size. These positive SLB results for 1941-1990 are like those obtained by Chan and Chen (1988) in tests on size portfolios for 1954-1983.

There is, however, evidence in Table AI that all is not well with the $\beta \mathrm{s}$ of the size portfolios. They do a fine job on the relation between size and average return, but they do a lousy job on their main task, the relation between $\beta$ and average return. When the residuals from the regressions of returns on $\beta$ are grouped using the pre-ranking $\beta \mathrm{s}$ of individual stocks, the average residuals are strongly positive for low- $\beta$ stocks $(0.51 \%$ per month for group $1 \mathrm{~A})$ and negative for high- $\beta$ stocks $(-1.05 \%$ for $10 \mathrm{~B})$. Thus the market lines estimated with size-portfolio $\beta \mathrm{s}$ exaggerate the tradeoff of average return for $\beta$; they underestimate average returns on low- $\beta$ stocks and overestimate average returns on high- $\beta$ stocks. This pattern in the $\beta$-sorted average residuals for individual stocks suggests that (a) there is variation in $\beta$ across stocks that is lost in the size portfolios, and (b) this variation in $\beta$ is not rewarded as well as the variation in $\beta$ that is related to size.

\section{B. Two-Pass Size- $\beta$ Portfolios}

Like Table I, Table AII shows that subdividing size deciles using the (pre-ranking) $\beta \mathrm{s}$ of individual stocks results in strong variation in $\beta$ that is 


\section{Average Returns, Post-Ranking $\beta$ s and Fama-MacBeth Regression Slopes for \\ Size Portfolios of NYSE Stocks: 1941-1990}

At the end of each year $t-1$, stocks are assigned to 12 portfolios using ranked values of ME. Included are all NYSE stocks that have a CRSP price and shares for December of year $t-1$ and returns for at least 24 of the 60 months ending in December of year $t-1$ (for pre-ranking $\beta$ estimates). The middle 8 portfolios cover size deciles 2 to 9 . The 4 extreme portfolios $(1 \mathrm{~A}, 1 \mathrm{~B}, 10 \mathrm{~A}$, and 10B) split the smallest and largest deciles in half. We compute equal-weighted returns on the portfolios for the 12 months of year $t$ using all surviving stocks. Average Return is the time-series average of the monthly portfolio returns for 1941-1990, in percent. Average firms is the average number of stocks in the portfolios each month. The simple $\beta$ s are estimated by regressing the 1941-1990 sample of post-ranking monthly returns for a size portfolio on the current month's value-weighted NYSE portfolio return. The sum $\beta \mathrm{s}$ are the sum of the slopes from a regression of the post-ranking monthly returns on the current and prior month's VW NYSE returns.

The independent variables in the Fama-MacBeth regressions are defined for each firm at the end of December of each year $t-1$. Stocks are assigned the post-ranking (sum) $\beta$ of the size portfolio they are in at the end of year $t-1$. ME is price times shares outstanding at the end of year $t-1$. In the individual-stock regressions, these values of the explanatory variables are matched with CRSP returns for each of the 12 months of year $t$. The portfolio regressions match the equal-weighted portfolio returns with the equal-weighted averages of $\beta$ and $\ln (\mathrm{ME})$ for the surviving stocks in each month of year $t$. Slope is the average of the (600) monthly FM regression slopes and SE is the standard error of the average slope. The residuals from the monthly regressions for year $t$ are grouped into 12 portfolios on the basis of size (ME) or pre-ranking $\beta$ (estimated with 24 to 60 months of data, as available) at the end of year $t-1$. The average residuals are the time-series averages of the monthly equal-weighted portfolio residuals, in percent. The average residuals for regressions (1) and (2) (not shown) are quite similar to those for regressions (4) and (5) (shown).

\begin{tabular}{|c|c|c|c|c|c|c|c|c|c|c|c|c|}
\hline \multicolumn{13}{|c|}{ Dortfolios Formed on Size } \\
\hline & $1 \mathrm{~A}$ & 1B & 2 & 3 & 4 & 5 & 6 & 7 & 8 & 9 & $10 \mathrm{~A}$ & $10 \mathrm{~B}$ \\
\hline Ave. return & 1.96 & 1.59 & 1.44 & 1.36 & 1.28 & 1.24 & 1.23 & 1.17 & 1.15 & 1.13 & 0.97 & 0.93 \\
\hline Ave. firms & 57 & 56 & 110 & 107 & 107 & 108 & 111 & 113 & 115 & 118 & 59 & 59 \\
\hline Simple $\beta$ & 1.29 & 1.24 & 1.21 & 1.19 & 1.16 & 1.13 & 1.13 & 1.12 & 1.09 & 1.05 & 1.00 & 0.98 \\
\hline Standard error & 0.07 & 0.05 & 0.04 & 0.03 & 0.02 & 0.02 & 0.02 & 0.02 & 0.01 & 0.01 & 0.01 & 0.01 \\
\hline $\operatorname{Sum} \beta$ & 1.60 & 1.44 & 1.37 & 1.32 & 1.26 & 1.23 & 1.19 & 1.17 & 1.12 & 1.06 & 0.99 & 0.95 \\
\hline Standard error & 0.10 & 0.06 & 0.05 & 0.04 & 0.03 & 0.03 & 0.03 & 0.02 & 0.02 & 0.01 & 0.01 & 0.01 \\
\hline
\end{tabular}


Table AI-Continued

\begin{tabular}{|c|c|c|c|c|c|c|c|c|c|c|c|c|}
\hline & \multicolumn{6}{|c|}{ Portfolio Regressions } & \multicolumn{6}{|c|}{ Individual Stock Regressions } \\
\hline & (1) $\beta$ & \multicolumn{2}{|c|}{ (2) $\ln (\mathrm{ME})$} & \multicolumn{3}{|c|}{ (3) $\beta$ and $\ln (\mathrm{ME})$} & (4) $\beta$ & \multicolumn{2}{|c|}{ (5) $\ln (\mathrm{ME})$} & \multicolumn{3}{|c|}{ (6) $\beta$ and $\ln (\mathrm{ME})$} \\
\hline \multirow{2}{*}{$\begin{array}{l}\text { Slope } \\
\text { SE }\end{array}$} & \multirow{2}{*}{$\begin{array}{l}1.45 \\
0.47\end{array}$} & \multirow{2}{*}{\multicolumn{2}{|c|}{$\begin{array}{r}-0.137 \\
0.044\end{array}$}} & 3.05 & \multirow{2}{*}{\multicolumn{2}{|c|}{$\begin{array}{l}0.149 \\
0.115\end{array}$}} & 1.39 & \multirow{2}{*}{\multicolumn{2}{|c|}{$\begin{array}{r}-0.133 \\
0.043\end{array}$}} & 0.71 & \multirow{2}{*}{\multicolumn{2}{|c|}{$\begin{array}{r}-0.060 \\
0.062\end{array}$}} \\
\hline & & & & 1.51 & & & 0.46 & & & 0.81 & & \\
\hline \multicolumn{13}{|c|}{ Average Residuals for Stocks Grouped on Size } \\
\hline & $1 \mathrm{~A}$ & $1 \mathrm{~B}$ & 2 & 3 & 4 & 5 & 6 & 7 & 8 & 9 & $10 \mathrm{~A}$ & $10 \mathrm{~B}$ \\
\hline Regression (4) & 0.17 & 0.00 & $-0,04$ & -0.06 & -0.05 & -0.04 & 0.00 & -0.03 & 0.03 & 0.08 & 0.01 & 0.04 \\
\hline Standard error & 0.11 & 0.06 & 0.04 & 0.04 & 0.04 & 0.04 & 0.03 & 0.03 & 0.03 & 0.03 & 0.05 & 0.06 \\
\hline Regression (5) & 0.30 & 0.02 & -0.05 & -0.06 & -0.08 & -0.07 & -0.03 & -0.04 & 0.02 & 0.08 & 0.01 & 0.13 \\
\hline Standard error & 0.14 & 0.07 & 0.04 & 0.04 & 0.04 & 0.04 & 0.04 & 0.03 & 0.03 & 0.03 & 0.04 & 0.07 \\
\hline Regression (6) & 0.20 & 0.02 & -0.05 & -0.07 & -0.08 & -0.06 & -0.01 & -0.02 & 0.04 & 0.09 & 0.00 & 0.06 \\
\hline Standard error & 0.10 & 0.06 & 0.04 & 0.04 & 0.04 & 0.04 & 0.03 & 0.03 & 0.03 & 0.03 & 0.05 & 0.05 \\
\hline \multicolumn{13}{|c|}{ Average Residuals for Stocks Grouped on Pre-Ranking $\beta$} \\
\hline & $1 \mathrm{~A}$ & $1 \mathrm{~B}$ & 2 & 3 & 4 & 5 & 6 & 7 & 8 & 9 & $10 \mathrm{~A}$ & $10 \mathrm{~B}$ \\
\hline Regression (4) & 0.51 & 0.61 & 0.38 & 0.32 & 0.16 & 0.12 & 0.03 & -0.10 & -0.27 & -0.31 & -0.66 & -1.05 \\
\hline Standard error & 0.21 & 0.19 & 0.13 & 0.08 & 0.04 & 0.03 & 0.04 & 0.05 & 0.09 & 0.11 & 0.18 & 0.23 \\
\hline Regression (5) & -0.10 & 0.00 & 0.02 & 0.09 & 0.05 & 0.07 & 0.05 & 0.00 & -0.03 & -0.01 & -0.11 & -0.33 \\
\hline Standard error & 0.11 & 0.10 & 0.07 & 0.05 & 0.04 & 0.03 & 0.03 & 0.04 & 0.05 & 0.07 & 0.10 & 0.13 \\
\hline Regression (6) & 0.09 & 0.25 & 0.13 & 0.19 & 0.11 & 0.14 & 0.09 & 0.01 & -0.11 & -0.12 & -0.38 & -0.70 \\
\hline Standard error & 0.41 & 0.37 & 0.24 & 0.14 & 0.07 & 0.04 & 0.04 & 0.09 & 0.16 & 0.21 & 0.34 & 0.43 \\
\hline
\end{tabular}


Table AII

Properties of Portfolios Formed on Size and Pre-Ranking $\beta$ : NYSE Stocks

Sorted by ME (Down) then Pre-Ranking $\beta$ (Across): 1941-1990

At the end of year $t-1$, the NYSE stocks on CRSP are assigned to 10 size (ME) portfolios. Each size decile is subdivided into $10 \beta$ portfolios using pre-ranking $\beta \mathrm{s}$ of individual stocks, estimated with 24 to 60 monthly returns (as available) ending in December of year $t-1$. The equal-weighted monthly returns on the resulting 100 portfolios are then calculated for year $t$. The average returns are the time-series averages of the monthly returns, in percent. The post-ranking $\beta \mathrm{s}$ use the full 1941-1990 sample of post-ranking returns for each portfolio. The pre- and post-ranking $\beta$ s are the sum of the slopes from a regression of monthly returns on the current and prior month's NYSE value-weighted market return. The average size for a portfolio is the time-series average of each month's average value of $\ln (\mathrm{ME})$ for stocks in the portfolio. ME is denominated in millions of dollars. There are, on average, about 10 stocks in each size- $\beta$ portfolio each month. The All column shows parameter values for equal-weighted size-decile (ME) portfolios. The All rows show parameter values for equal-weighted portfolios of the stocks in each $\beta$ group.

\begin{tabular}{lcccccccccccc}
\hline & All & Low- $\beta$ & $\beta-2$ & $\beta-3$ & $\beta-4$ & $\beta-5$ & $\beta-6$ & $\beta-7$ & $\beta-8$ & $\beta-9$ & High- $\beta$ \\
\hline & & \multicolumn{7}{c}{ Panel A: Average Monthly Return (in Percent) } \\
\hline All & & 1.22 & 1.30 & 1.32 & 1.35 & 1.36 & 1.34 & 1.29 & 1.34 & 1.14 & 1.10 \\
Small-ME & 1.78 & 1.74 & 1.76 & 2.08 & 1.91 & 1.92 & 1.72 & 1.77 & 1.91 & 1.56 & 1.46 \\
ME-2 & 1.44 & 1.41 & 1.35 & 1.33 & 1.61 & 1.72 & 1.59 & 1.40 & 1.62 & 1.24 & 1.11 \\
ME-3 & 1.36 & 1.21 & 1.40 & 1.22 & 1.47 & 1.34 & 1.51 & 1.33 & 1.57 & 1.33 & 1.21 \\
ME-4 & 1.28 & 1.26 & 1.29 & 1.19 & 1.27 & 1.51 & 1.30 & 1.19 & 1.56 & 1.18 & 1.00 \\
ME-5 & 1.24 & 1.22 & 1.30 & 1.28 & 1.33 & 1.21 & 1.37 & 1.41 & 1.31 & 0.92 & 1.06 \\
ME-6 & 1.23 & 1.21 & 1.32 & 1.37 & 1.09 & 1.34 & 1.10 & 1.40 & 1.21 & 1.22 & 1.08 \\
ME-7 & 1.17 & 1.08 & 1.23 & 1.37 & 1.27 & 1.19 & 1.34 & 1.10 & 1.11 & 0.87 & 1.17 \\
ME-8 & 1.15 & 1.06 & 1.18 & 1.26 & 1.25 & 1.26 & 1.17 & 1.16 & 1.05 & 1.08 & 1.04 \\
ME-9 & 1.13 & 0.99 & 1.13 & 1.00 & 1.24 & 1.28 & 1.31 & 1.15 & 1.11 & 1.09 & 1.05 \\
Large-ME & 0.95 & 0.99 & 1.01 & 1.12 & 1.01 & 0.89 & 0.95 & 0.95 & 1.00 & 0.90 & 0.68
\end{tabular}


Table AII-Continued

\begin{tabular}{|c|c|c|c|c|c|c|c|c|c|c|c|}
\hline & All & Low $-\beta$ & $\beta-2$ & $\beta-3$ & $\beta-4$ & $\beta-5$ & $\beta-6$ & $\beta-7$ & $\beta-8$ & $\beta-9$ & High $-\beta$ \\
\hline \multicolumn{12}{|c|}{ Panel B: Post-Ranking $\beta$} \\
\hline All & & 0.76 & 0.95 & 1.05 & 1.14 & 1.22 & 1.26 & 1.34 & 1.38 & 1.49 & 1.69 \\
\hline Small-ME & 1.52 & 1.17 & 1.40 & 1.31 & 1.50 & 1.46 & 1.50 & 1.69 & 1.60 & 1.75 & 1.92 \\
\hline ME-2 & 1.37 & 0.86 & 1.09 & 1.12 & 1.24 & 1.39 & 1.42 & 1.48 & 1.60 & 1.69 & 1.91 \\
\hline ME-3 & 1.32 & 0.88 & 0.96 & 1.18 & 1.19 & 1.33 & 1.40 & 1.43 & 1.56 & 1.64 & 1.74 \\
\hline $\mathrm{ME}-4$ & 1.26 & 0.69 & 0.95 & 1.06 & 1.15 & 1.24 & 1.29 & 1.46 & 1.43 & 1.64 & 1.83 \\
\hline ME-5 & 1.23 & 0.70 & 0.95 & 1.04 & 1.10 & 1.22 & 1.32 & 1.34 & 1.41 & 1.56 & 1.72 \\
\hline ME-6 & 1.19 & 0.68 & 0.86 & 1.04 & 1.13 & 1.20 & 1.20 & 1.35 & 1.36 & 1.48 & 1.70 \\
\hline ME-7 & 1.17 & 0.67 & 0.88 & 0.95 & 1.14 & 1.18 & 1.26 & 1.27 & 1.32 & 1.44 & 1.68 \\
\hline ME-8 & 1.12 & 0.64 & 0.83 & 0.99 & 1.06 & 1.14 & 1.14 & 1.21 & 1.26 & 1.39 & 1.58 \\
\hline ME-9 & 1.06 & 0.68 & 0.81 & 0.94 & 0.96 & 1.06 & 1.11 & 1.18 & 1.22 & 1.25 & 1.46 \\
\hline Large-ME & 0.97 & 0.65 & 0.73 & 0.90 & 0.91 & 0.97 & 1.01 & 1.01 & 1.07 & 1.12 & 1.38 \\
\hline \multicolumn{12}{|c|}{ Panel C: Average Size (ln(ME)) } \\
\hline All & & 4.39 & 4.39 & 4.40 & 4.40 & 4.39 & 4.40 & 4.38 & 4.37 & 4.37 & 4.34 \\
\hline Small-ME & 1.93 & 2.04 & 1.99 & 2.00 & 1.96 & 1.92 & 1.92 & 1.91 & 1.90 & 1.87 & 1.80 \\
\hline ME-2 & 2.80 & 2.81 & 2.79 & 2.81 & 2.83 & 2.80 & 2.79 & 2.80 & 2.80 & 2.79 & 2.79 \\
\hline ME-3 & 3.27 & 3.28 & 3.27 & 3.28 & 3.27 & 3.27 & 3.28 & 3.29 & 3.27 & 3.27 & 3.26 \\
\hline $\mathrm{ME}-4$ & 3.67 & 3.67 & 3.67 & 3.67 & 3.68 & 3.68 & 3.67 & 3.68 & 3.66 & 3.67 & 3.67 \\
\hline ME-5 & 4.06 & 4.07 & 4.06 & 4.05 & 4.06 & 4.07 & 4.06 & 4.05 & 4.05 & 4.06 & 4.06 \\
\hline ME-6 & 4.45 & 4.45 & 4.44 & 4.46 & 4.45 & 4.45 & 4.45 & 4.45 & 4.44 & 4.45 & 4.45 \\
\hline ME-7 & 4.87 & 4.86 & 4.87 & 4.86 & 4.87 & 4.87 & 4.88 & 4.87 & 4.87 & 4.85 & 4.87 \\
\hline ME-8 & 5.36 & 5.38 & 5.38 & 5.38 & 5.35 & 5.36 & 5.37 & 5.37 & 5.36 & 5.35 & 5.34 \\
\hline ME-9 & 5.98 & 5.96 & 5.98 & 5.99 & 6.00 & 5.98 & 5.98 & 5.97 & 5.95 & 5.96 & 5.96 \\
\hline Large-ME & 7.12 & 7.10 & 7.12 & 7.16 & 7.17 & 7.20 & 7.29 & 7.14 & 7.09 & 7.04 & 6.83 \\
\hline
\end{tabular}


independent of size. The $\beta$ sort of a size decile always produces portfolios with similar average $\ln (\mathrm{ME})$ but muck. different (post-ranking) $\beta$ s. Table AII also shows, however, that investors are not compensated for the variation in $\beta$ that is independent of size. Despite the wide range of $\beta \mathrm{s}$ in each size decile, average returns show no tendency to increase with $\beta$. AII

The FM regressions in Table AIII formalize the roles of size and $\beta$ in NYSE average returns for 1941-1990. The regressions of returns on $\beta$ alone show that using the $\beta \mathrm{s}$ of the portfolios formed on size and $\beta$, rather than size alone, causes the average slope on $\beta$ to fall from about $1.4 \%$ per month (Table AI) to about $0.23 \%$ (about 1 standard error from 0 ). Thus, allowing for variation in $\beta$ that is unrelated to size flattens the relation between average return and $\beta$, to the point where it is indistinguishable from no relation at all.

The flatter market lines in Table AIII succeed, however, in erasing the negative relation between $\beta$ and average residuals observed in the regressions of returns on $\beta$ alone in Table AI. Thus, forming portfolios on size and $\beta$ (Table AIII) produces a better description of the simple relation between average return and $\beta$ than forming portfolios on size alone (Table AI). This improved description of the relation between average return and $\beta$ is evidence that the $\beta$ estimates for the two-pass size- $\beta$ portfolios capture variation in true $\beta$ s that is missed when portfolios are formed on size alone.

Unfortunately, the flatter market lines in Table AIII have a cost, the emergence of a residual size effect. Grouped on the basis of ME for individual stocks, the average residuals from the univariate regressions of returns on the $\beta \mathrm{s}$ of the 100 size- $\beta$ portfolios are strongly positive for small stocks and negative for large stocks $(0.60 \%$ per month for the smallest ME group, $1 \mathrm{~A}$, and $-0.27 \%$ for the largest, 10B). Thus, when we allow for variation in $\beta$ that is independent of size, the resulting $\beta$ s leave a large size effect in average returns. This residual size effect is much like that observed by Banz (1981) with the $\beta$ s of portfolios formed on size and $\beta$.

The correlation between size and $\beta$ is -0.98 for portfolios formed on size alone. The independent variation in $\beta$ obtained with the second-pass sort on $\beta$ lowers the correlation to -0.50 . The lower correlation means that bivariate regressions of returns on $\beta$ and $\ln (\mathrm{ME})$ are more likely to distinguish true size effects from true $\beta$ effects in average returns.

The bivariate regressions (Table AIII) that use the $\beta$ s of the size- $\beta$ portfolios are more bad news for $\beta$. The average slopes for $\ln (\mathrm{ME})$ are close to the values in the univariate size regressions, and almost 4 standard errors from 0 , but the average slopes for $\beta$ are negative and less than 1 standard error from 0 . The message from the bivariate regressions is that there is a strong relation between size and average return. But like the regressions in Table AIII that explain average returns with $\beta$ alone, the bivariate regressions say that there is no reliable relation between $\beta$ and average returns when the tests use $\beta$ s that are not close substitutes for size. These uncomfortable SLB results for NYSE stocks for 1941-1990 are much like those for NYSE, AMEX, and NASDAQ stocks for 1963-1990 in Table III. 


\section{Subperiod Diagnostics}

Our results for 1941-1990 seem to contradict the evidence in Black, Jensen, and Scholes (BJS) (1972) and Fama and MacBeth (FM) (1973) that there is a reliable positive relation between average return and $\beta$. The $\beta \mathrm{s}$ in BJS and FM are from portfolios formed on $\beta$ alone, and the market proxy is the NYSE equal-weighted portfolio. We use the $\beta \mathrm{s}$ of portfolios formed on size and $\beta$, and our market is the value-weighted NYSE portfolio. We can report, however, that our inference that there isn't much relation between $\beta$ and average return is unchanged when (a) the market proxy is the NYSE EW portfolio, (b) portfolios are formed on just (pre-ranking) $\beta \mathrm{s}$, or (c) the order of forming the size- $\beta$ portfolios is changed from size then $\beta$ to $\beta$ then size.

A more important difference between our results and the earlier studies is the sample periods. The tests in BJS and FM end in the 1960s. Table AIV shows that when we split the 50-year 1941-1990 period in half, the univariate FM regressions of returns on $\beta$ produce an average slope for 1941-1965 $(0.50 \%$ per month, $t=1.82)$ more like that of the earlier studies. In contrast, the average slope on $\beta$ for $1966-1990$ is close to $0(-0.02, t=0.06)$.

But Table AIV also shows that drawing a distinction between the results for 1941-1965 and 1966-1990 is misleading. The stronger tradeoff of average return for $\beta$ in the simple regressions for $1941-1965$ is due to the first 10 years, 1941-1950. This is the only period in Table AIV that produces an average premium for $\beta(1.26 \%$ per month) that is both positive and more than 2 standard errors from 0 . Conversely, the weak relation between $\beta$ and average return for 1966-1990 is largely due to 1981-1990. The strong negative average slope in the univariate regressions of returns on $\beta$ for 1981-1990 $(-1.01, t=-2.10)$ offsets a positive slope for 1971-1980 (0.82, $t=1.27)$.

The subperiod variation in the average slopes from the FM regressions of returns on $\beta$ alone seems moot, however, given the evidence in Table AIV that adding size always kills any positive tradeoff of average return for $\beta$ in the subperiods. Adding size to the regressions for 1941-1965 causes the average slope for $\beta$ to drop from $0.50(t=1.82)$ to $0.07(t=0.28)$. In contrast, the average slope on size in the bivariate regressions $(-0.16, t=-2.97)$ is close to its value $(-0.17, t=-2.88)$ in the regressions of returns on $\ln (\mathrm{ME})$ alone. Similar comments hold for 1941-1950. In short, any evidence of a positive average premium for $\beta$ in the subperiods seems to be a size effect in disguise.

\section{Can the SLB Model Be Saved?}

Before concluding that $\beta$ has no explanatory power, it is appropriate to consider other explanations for our results. One possibility is that the variation in $\beta$ produced by the $\beta$ sorts of size deciles in just sampling error. If so, it is not surprising that the variation in $\beta$ within a size decile is unrelated to average return, or that size dominates $\beta$ in bivariate tests. The standard errors of the $\beta$ s suggest, however, that this explanation cannot save the SLB 
Table AIII

Average Slopes, Their Standard Errors (SE), and Average Residuals from Monthly FM Regressions for Individual NYSE Stocks and for Portfolios Formed

\section{on Size and Pre-Ranking $\beta$ : 1941-1990}

Stocks are assigned the post-ranking $\beta$ of the size- $\beta$ portfolio they are in at the end of year $t-1$ (Table AII). $\ln (\mathrm{ME})$ is the natural log of price times shares outstanding at the end of year $t-1$. In the individual-stock regressions, these values of the explanatory variables are matched with CRSP returns for each of the 12 months in year $t$. The portfolio regressions match the equal-weighted portfolio returns for the size- $\beta$ portfolios (Table AII) with the equal-weighted averages of $\beta$ and $\ln (\mathrm{ME})$ for the surviving stocks in each month of year $t$. Slope is the time-series average of the monthly regression slopes from 1941-1990 (600 months); SE is the time-series standard error of the average slope.

The residuals from the monthly regressions in year $t$ are grouped into 12 portfolios on the basis of size or pre-ranking $\beta$ (estimated with 24 to 60 months of returns, as available) as of the end of year $t-1$. The average residuals are the time-series averages of the monthly equal-weighted averages of the residuals in percent. The average residuals (not shown) from the FM regressions (1) to (3) that use the returns on the 100 size- $\beta$ portfolios as the dependent variable are always within 0.01 of those from the regressions for individual stock returns. This is not surprising given that the correlation between the time-series of 1941-1990 monthly FM slopes on $\beta$ or $\ln (\mathrm{ME})$ for the comparable portfolio and individual stock regressions is always greater than 0.99 .

\begin{tabular}{|c|c|c|c|c|c|c|c|c|}
\hline \multirow[b]{3}{*}{ Slope } & \multicolumn{4}{|c|}{ Portfolio Regressions } & \multicolumn{4}{|c|}{ Individual Stock Regressions } \\
\hline & \multirow{2}{*}{$\begin{array}{l}(1) \beta \\
0.22\end{array}$} & \multirow{2}{*}{$\begin{array}{c}(2) \ln (\mathrm{ME}) \\
-0.128\end{array}$} & \multicolumn{2}{|c|}{ (3) $\beta$ and $\ln (\mathrm{ME})$} & \multirow{2}{*}{$\frac{(4) \beta}{0.24}$} & \multirow{2}{*}{$\begin{array}{c}\text { (5) } \ln (\mathrm{ME}) \\
-0.133\end{array}$} & \multicolumn{2}{|c|}{ (6) $\beta$ and $\ln (\mathrm{ME})$} \\
\hline & & & -0.13 & -0.143 & & & -0.14 & -0.147 \\
\hline $\mathrm{SE}$ & 0.24 & 0.043 & 0.21 & 0.039 & 0.23 & 0.043 & 0.21 & 0.039 \\
\hline
\end{tabular}

\begin{tabular}{|c|c|c|c|c|c|c|c|c|c|c|c|c|}
\hline \multicolumn{13}{|c|}{ Average Residuals for Stocks Grouped on Size } \\
\hline & $1 \mathrm{~A}$ & 1B & 2 & 3 & 4 & 5 & 6 & 7 & 8 & 9 & $10 \mathrm{~A}$ & 10B \\
\hline Regression (4) & 0.60 & 0.26 & 0.13 & 0.06 & -0.01 & -0.03 & -0.03 & -0.09 & -0.10 & -0.11 & -0.25 & -0.27 \\
\hline Standard error & 0.21 & 0.10 & 0.06 & 0.04 & 0.04 & 0.04 & 0.04 & 0.04 & 0.04 & 0.05 & 0.06 & 0.08 \\
\hline Regression (5) & 0.30 & 0.02 & -0.05 & -0.06 & -0.08 & -0.07 & -0.03 & -0.04 & 0.02 & 0.08 & 0.01 & 0.13 \\
\hline Standard error & 0.14 & 0.07 & 0.04 & 0.04 & 0.04 & 0.04 & 0.04 & 0.03 & 0.03 & 0.03 & 0.04 & 0.07 \\
\hline Regression (6) & 0.31 & 0.02 & -0.05 & -0.06 & -0.09 & -0.07 & -0.03 & -0.04 & 0.02 & 0.08 & 0.01 & 0.13 \\
\hline Standard error & 0.14 & 0.07 & 0.04 & 0.04 & 0.04 & 0.04 & 0.04 & 0.03 & 0.03 & 0.03 & 0.04 & 0.07 \\
\hline
\end{tabular}


Table AIII-Continued

\begin{tabular}{|c|c|c|c|c|c|c|c|c|c|c|c|c|}
\hline & \multicolumn{6}{|c|}{ Portfolio Regressions } & \multicolumn{6}{|c|}{ Individual Stock Regressions } \\
\hline & (1) $\beta$ & \multicolumn{2}{|c|}{$(2) \ln (\mathrm{ME})$} & \multicolumn{3}{|c|}{ (3) $\beta$ and $\ln (\mathrm{ME})$} & (4) $\beta$ & \multicolumn{2}{|c|}{ (5) $\ln (\mathrm{ME})$} & \multicolumn{3}{|c|}{ (6) $\beta$ and $\ln (\mathrm{ME})$} \\
\hline \multicolumn{13}{|c|}{ Average Residuals for Stocks Grouped on Pre-Ranking $\beta$} \\
\hline & $1 \mathrm{~A}$ & 1B & 2 & 3 & 4 & 5 & 6 & 7 & 8 & 9 & $10 \mathrm{~A}$ & $10 \mathrm{~B}$ \\
\hline Regression (4) & -0.08 & 0.03 & -0.01 & 0.08 & 0.04 & 0.08 & 0.04 & 0.02 & -0.03 & 0.02 & -0.11 & -0.32 \\
\hline Standard error & 0.07 & 0.05 & 0.03 & 0.03 & 0.03 & 0.03 & 0.04 & 0.04 & 0.04 & 0.04 & 0.06 & 0.07 \\
\hline Regression (5) & -0.10 & 0.00 & 0.02 & 0.09 & 0.05 & 0.07 & 0.05 & 0.00 & -0.03 & -0.01 & -0.11 & -0.33 \\
\hline Standard error & 0.11 & 0.10 & 0.07 & 0.05 & 0.04 & 0.03 & 0.03 & 0.04 & 0.05 & 0.07 & 0.10 & 0.13 \\
\hline Regression (6) & -0.17 & -0.07 & -0.02 & 0.07 & 0.04 & 0.06 & 0.05 & 0.03 & 0.00 & 0.04 & -0.04 & -0.23 \\
\hline Standard error & 0.05 & 0.04 & 0.03 & 0.03 & 0.03 & 0.03 & 0.03 & 0.03 & 0.04 & 0.04 & 0.06 & 0.07 \\
\hline
\end{tabular}


Table AIV

Subperiod Average Returns on the NYSE Value-Weighted and

Equal-Weighted Portfolios and Average Values of the

Intercepts and Slopes for the FM Cross-Sectional Regressions of Individual Stock Returns on $\beta$ and Size $(\ln (\mathrm{ME}))$

Mean is the average VW or EW return or an average slope from the monthly cross-sectional regressions of individual stock returns on $\beta$ and/or $\ln (\mathrm{ME})$. Std is the standard deviation of the time-series of returns or slopes, and $t(\mathrm{Mn})$ is Mean over its time-series standard error. The average slopes (not shown) from the FM regressions that use the returns on the 100 size- $\beta$ portfolios of Table AII as the dependent variable are quite close to those for individual stock returns. (The correlation between the 1941-1990 month-by-month slopes on $\beta$ or $\ln (\mathrm{ME})$ for the comparable portfolio and individual stock regressions is always greater than 0.99 .)

\begin{tabular}{|c|c|c|c|c|c|c|c|c|c|}
\hline \multicolumn{10}{|c|}{ Panel A } \\
\hline & \multicolumn{3}{|c|}{$1941-1990$ (600 Mos.) } & \multicolumn{3}{|c|}{ 1941-1965 (300 Mos.) } & \multicolumn{3}{|c|}{ 1966-1990 (300 Mos.) } \\
\hline Variable & Mean & Std & $t(\mathrm{Mn})$ & Mean & Std & $t(\mathrm{Mn})$ & Mean & Std & $t(\mathrm{Mn})$ \\
\hline \multicolumn{10}{|c|}{ NYSE Value-Weighted (VW) and Equal-Weighted (EW) Portfolio Returns } \\
\hline VW & 0.93 & 4.15 & 5.49 & 1.10 & 3.58 & 5.30 & 0.76 & 4.64 & 2.85 \\
\hline EW & 1.12 & 5.10 & 5.37 & 1.33 & 4.42 & 5.18 & 0.91 & 5.70 & 2.77 \\
\hline \multicolumn{10}{|c|}{$R_{\imath t}=\mathrm{a}+\mathrm{b}_{1 t} \beta_{\imath t}+e_{\imath t}$} \\
\hline a & 0.98 & 3.93 & 6.11 & 0.84 & 3.18 & 4.56 & 1.13 & 4.57 & 4.26 \\
\hline$b_{1}$ & 0.24 & 5.52 & 1.07 & 0.50 & 4.75 & 1.82 & -0.02 & 6.19 & -0.06 \\
\hline \multicolumn{10}{|c|}{$R_{i t}=\mathrm{a}+\mathrm{b}_{2 t} \ln \left(\mathrm{ME}_{i t}\right)+e_{i t}$} \\
\hline a & 1.70 & 8.24 & 5.04 & 1.88 & 6.43 & 5.06 & 1.51 & 9.72 & 2.69 \\
\hline $\mathrm{b}_{2}$ & -0.13 & 1.06 & -3.07 & -0.17 & 1.01 & -2.88 & -0.10 & 1.11 & -1.54 \\
\hline \multicolumn{10}{|c|}{$R_{\imath t}=\mathrm{a}+\mathrm{b}_{1 t} \beta_{\imath t}+\mathrm{b}_{2 t} \ln \left(\mathrm{ME}_{\imath t}\right)+e_{\imath t}$} \\
\hline $\mathrm{a}$ & 1.97 & 6.16 & 7.84 & 1.80 & 4.77 & 6.52 & 2.14 & 7.29 & 5.09 \\
\hline $\mathrm{b}_{1}$ & -0.14 & 5.05 & -0.66 & 0.07 & 4.15 & 0.28 & -0.34 & 5.80 & -1.01 \\
\hline$b_{2}$ & -0.15 & 0.96 & -3.75 & -0.16 & 0.94 & -2.97 & -0.13 & 0.99 & -2.34 \\
\hline
\end{tabular}


Table AIV-Continued

Panel B

\begin{tabular}{|c|c|c|c|c|c|c|c|c|c|c|}
\hline \multirow[b]{2}{*}{ Return } & \multicolumn{2}{|c|}{$1941-1950$} & \multicolumn{2}{|c|}{$1951-1960$} & \multicolumn{2}{|c|}{$1961-1970$} & \multicolumn{2}{|c|}{$1971-1980$} & \multicolumn{2}{|c|}{$1981-1990$} \\
\hline & Mean & $t(\mathrm{Mn})$ & Mean & $t(\mathrm{Mn})$ & Mean & $t(\mathrm{Mn})$ & Mean & $t(\mathrm{Mn})$ & Mean & $t(\mathrm{Mn})$ \\
\hline \multicolumn{11}{|c|}{ NYSE Value-Weighted (VW) and Equal-Weighted (EW) Portfolio Returns } \\
\hline VW & 1.05 & 2.88 & 1.18 & 3.95 & 0.66 & 1.84 & 0.72 & 1.67 & 1.04 & 2.40 \\
\hline EW & 1.59 & 3.16 & 1.13 & 3.76 & 0.88 & 1.96 & 1.04 & 1.82 & 0.95 & 2.01 \\
\hline \multicolumn{11}{|c|}{$R_{i t}=\mathrm{a}+\mathrm{b}_{1 t} \beta_{i t}+e_{i t}$} \\
\hline a & 0.24 & 0.66 & 1.41 & 6.36 & 0.64 & 1.94 & 0.27 & 0.62 & 2.35 & 5.99 \\
\hline $\mathrm{b}_{1}$ & 1.26 & 2.20 & -0.19 & -0.63 & 0.32 & 0.72 & 0.82 & 1.27 & -1.01 & -2.10 \\
\hline \multicolumn{11}{|c|}{$R_{i t}=\mathrm{a}+\mathrm{b}_{2 t} \ln \left(\mathrm{ME}_{\imath t}\right)+e_{\imath t}$} \\
\hline a & 2.63 & 3.47 & 1.08 & 2.73 & 1.78 & 2.50 & 2.18 & 2.03 & 0.82 & 1.20 \\
\hline $\mathrm{b}_{2}$ & -0.37 & -2.90 & 0.03 & 0.53 & -0.17 & -2.19 & -0.20 & -1.57 & 0.04 & 0.57 \\
\hline \multicolumn{11}{|c|}{$R_{\imath t}=\mathrm{a}+\mathrm{b}_{1 t} \beta_{\imath t}+\mathrm{b}_{2 t} \ln \left(\mathrm{ME}_{\imath t}\right)+e_{\imath t}$} \\
\hline a & 2.14 & 3.93 & 1.38 & 4.03 & 2.01 & 4.16 & 1.50 & 2.12 & 2.84 & 4.25 \\
\hline $\mathrm{b}_{1}$ & 0.34 & 0.75 & -0.17 & -0.53 & -0.11 & -0.27 & 0.41 & 0.75 & -1.14 & -2.16 \\
\hline $\mathrm{b}_{2}$ & -0.34 & -2.92 & 0.01 & 0.20 & -0.18 & -2.89 & -0.16 & -1.50 & -0.07 & -0.84 \\
\hline
\end{tabular}


model. The standard errors for portfolios formed on size and $\beta$ are only slightly larger (0.02 to 0.11$)$ than those for portfolios formed on size alone ( 0.01 to 0.10 , Table AI). And the range of the post-ranking $\beta \mathrm{s}$ within a size decile is always large relative to the standard errors of the $\beta \mathrm{s}$.

Another possibility is that the proportionality condition (1) for the variation through time in true $\beta \mathrm{s}$, that justifies the use of full-period post-ranking $\beta \mathrm{s}$ in the FM tests, does not work well for portfolios formed on size and $\beta$. If this is a problem, post-ranking $\beta$ s for the size- $\beta$ portfolios should not be highly correlated across subperiods. The correlation between the half-period (1941-1965 and 1966-1990) $\beta$ s of the size- $\beta$ portfolios is 0.91 , which we take to be good evidence that the full-period $\beta$ estimates for these portfolios are informative about true $\beta \mathrm{s}$. We can also report that using 5-year $\beta$ s (pre- or post-ranking) in the FM regressions does not change our negative conclusions about the role of $\beta$ in average returns, as long as portfolios are formed on $\beta$ as well as size, or on $\beta$ alone.

Any attempt to salvage the simple positive relation between $\beta$ and average return predicted by the SLB model runs into three damaging facts, clear in Table AII. (a) Forming portfolios on size and pre-ranking $\beta$ s produces a wide range of post-ranking $\beta \mathrm{s}$ in every size decile. (b) The post-ranking $\beta$ s closely reproduce (in deciles 2 to 10 they exactly reproduce) the ordering of the pre-ranking $\beta$ s used to form the $\beta$-sorted portfolios. It seems safe to conclude that the increasing pattern of the post-ranking $\beta \mathrm{s}$ in every size decile captures the ordering of the true $\beta \mathrm{s}$. (c) Contrary to the SLB model, the $\beta$ sorts do not produce a similar ordering of average returns. Within the rows (size deciles) of the average return matrix in Table AII, the high- $\beta$ portfolios have average returns that are close to or less than the low- $\beta$ portfolios.

But the most damaging evidence against the SLB model comes from the univariate regressions of returns on $\beta$ in Table AIII. They say that when the tests allow for variation in $\beta$ that is unrelated to size, the relation between $\beta$ and average return for 1941-1990 is weak, perhaps nonexistent, even when $\beta$ is the only explanatory variable. We are forced to conclude that the SLB model does not describe the last 50 years of average stock returns.

\section{REFERENCES}

Alford, Andrew, Jennifer J. Jones, and Mark E. Zmijewski, 1992, Extensions and violations of the statutory SEC Form 10-K filing date, Unpublished manuscript, University of Chicago, Chicago, IL.

Ball, Ray, 1978, Anomalies in relationships between securities' yields and yield-surrogates, Journal of Financial Economics 6, 103-126.

Banz, Rolf W., 1981, The relationship between return and market value of common stocks, Journal of Financial Economics 9, 3-18.

Basu, Sanjoy, 1983, The relationship between earnings yield, market value, and return for NYSE common stocks: Further evidence, Journal of Financial Economics 12, 129-156.

Bhandari, Laxmi Chand, 1988, Debt/Equity ratio and expected common stock returns: Empirical evidence, Journal of Finance 43, 507-528.

Black, Fischer, 1972, Capital market equilibrium with restricted borrowing, Journal of Business 45, 444-455. 
Michael C. Jensen, and Myron Scholes, 1972, The capital asset pricing model: some empirical tests, in M. Jensen, ed.: Studies in the Theory of Capital Markets (Praeger).

Chan, Louis K., Yasushi Hamao, and Josef Lakonishok, 1991, Fundamentals and stock returns in Japan, Journal of Finance 46, 1739-1789.

Chan, K. C. and Nai-fu Chen, 1988, An unconditional asset-pricing test and the role of firm size as an instrumental variable for risk, Journal of Finance 43, 309-325.

- , and Nai-fu Chen, 1991, Structural and return characteristics of small and large firms, Journal of Finance 46, 1467-1484.

— - Nai-fu Chen, and David A. Hsieh, 1985, An exploratory investigation of the firm size effect, Journal of Financial Economics 14, 451-471.

Chen, Nai-fu, Richard Roll, and Stephen A. Ross, 1986, Economic forces and the stock market, Journal of Business 56, 383-403.

DeBondt, Werner F. M., and Richard H. Thaler, 1985, Does the stock market overreact, Journal of Finance 40, 557-581.

Dimson, Elroy, 1979, Risk measurement when shares are subject to infrequent trading, Journal of Financial Economics 7, 197-226.

Fama, Eugene F., 1976, Foundations of Finance (Basic Books, New York).

- , and James MacBeth, 1973, Risk, return and equilibrium: Empirical tests, Journal of Political Economy 81, 607-636.

Fowler, David J. and C. Harvey Rorke, 1983, Risk measurement when shares are subject to infrequent trading: Comment, Journal of Financial Economics 12, 279-283.

Jaffe, Jeffrey, Donald B. Keim, and Randolph Westerfield, 1989, Earnings yields, market values, and stock returns, Journal of Finance 44, 135-148.

Keim, Donald B., 1983, Size-related anomalies and stock return seasonality, Journal of Financial Economics 12, 13-32.

, 1988, Stock market regularities: A synthesis of the evidence and explanations, in Elroy Dimson, ed.: Stock Market Anomalies (Cambridge University Press, Cambridge).

Lakonishok, Josef, and Alan C. Shapiro, 1986, Systematic risk, total risk and size as determinants of stock market returns, Journal of Banking and Finance 10, 115-132.

Lintner, John, 1965, The valuation of risk assets and the selection of risky investments in stock portfolios and capital budgets, Review of Economics and Statistics 47, 13-37.

Markowitz, Harry, 1959, Portfolio Selection: Efficient Diversification of Investments (Wiley, New York).

Merton, Robert C., 1973, An intertemporal capital asset pricing model, Econometrica 41, 867-887.

Reinganum, Marc R., 1981, A new empirical perspective on the CAPM, Journal of Financial and Quantitative Analysis 16, 439-462.

Roll, Richard, 1983, Vas ist Das? The turn-of-the-year effect and the return premia of small firms, Journal of Portfolio Management 9, 18-28.

Rosenberg, Barr, Kenneth Reid, and Ronald Lanstein, 1985, Persuasive evidence of market inefficiency, Journal of Portfolio Management 11, 9-17.

Ross, Stephen A., 1976, The arbitrage theory of capital asset pricing, Journal of Economic Theory 13, 341-360.

Sharpe, William F., 1964, Capital asset prices: a theory of market equilibrium under conditions of risk, Journal of Finance 19, 425-442.

Stambaugh, Robert F., 1982, On the exclusion of assets from tests of the two-parameter model: A sensitivity analysis, Journal of Financial Economics 10, 237-268.

Stattman, Dennis, 1980, Book values and stock returns, The Chicago MBA: A Journal of Selected Papers 4, 25-45. 